\title{
Does a high level of multimodality mean less car use? An exploration of multimodality trends in England
}

\author{
Eva Heinen $^{1}$ (D) Giulio Mattioli ${ }^{1,2}$
}

Published online: 19 August 2017

(C) The Author(s) 2017. This article is an open access publication

\begin{abstract}
Some existing studies have suggested that a higher level of multimodality-the use of more than one transport mode within a given period of time-may be desirable to achieve societies less dependent on cars. The aim of this study was to investigate the trends in individual multimodality in England. In addition, we explored whether these trends were homogenous, i.e. similar between socio-economic characteristics, and whether changes in multimodality corresponded with changes in car use and the use of other transport modes. Our analyses showed that in contrast to reported trends in existing research, the level of multimodality in England decreased between 1995 and 2015. These trends stratified by income were diverging, which may imply that inequality in transport opportunities may be increasing. In contrast, the trends for age and gender were converging. In addition, we found that the car mode share remained fairly stable and absolute car use decreased since 2004, whilst multimodality decreased. This suggests that there is no necessary relationship between aggregate levels of car use and the average individual level of multimodality. Moreover, our analyses showed that these trends were very similarly independent of which indicator was applied. This indicates that for analysing trends in multimodality, the choice of indicator may not be that important, and indicators that are elementary to calculate and easy to interpret, e.g. number of modes used, highlight trends that are highly consistent with more sophisticated metrics. This paper finishes with a discussion of the implications of these findings.
\end{abstract}

Eva Heinen

e.heinen@leeds.ac.uk

Giulio Mattioli

G.Mattioli@leeds.ac.uk

1 Faculty of the Environment, Institute for Transport Studies, University of Leeds, Leeds LS2 9JT, UK

2 Faculty of the Environment, Sustainability Research Institute and Institute for Transport Studies, University of Leeds, Leeds LS2 9JT, UK 
Keywords Trends $\cdot$ Multimodality $\cdot$ Car use $\cdot$ Social inequality $\cdot$ Travel behaviour

\section{Introduction}

In order to promote a sustainable and healthy environment, the dominance of the car needs to be reduced and a larger proportion of travel needs to be made by public transport, on foot, and by bicycle. In the developed world, policies have aimed to generate a modal shift away from the car with initiatives that include subsidies, improving the facilities for active travel and public transport, and restricting car access. Recently, increased policy attention has been placed on encouraging a partial shift rather than a full modal shift (EC 2014). The idea is to induce travellers to use the car for only some of their trips, whilst taking advantage of other modes in circumstances where they are sufficiently competitive.

In the scientific debate, the use of more than one transport mode within a given period of time, referred to as multimodality, has gained increasing attention (e.g. Buehler and Hamre 2015; Heinen and Chatterjee 2015; Susilo and Axhausen 2014; Kroesen 2015; Scheiner et al. 2016; Olafsson et al. 2016; Block-Schachter 2009). Some of these studies have even suggested that multimodality may be a predictor of behavioural change (Kroesen 2015; Heinen and Ogilvie 2016). These findings suggest that a higher level of multimodality may therefore be desirable to achieve societies less dependent on cars.

The majority of the studies have focussed on the correlates of multimodality, (e.g. Susilo and Axhausen 2014; Heinen and Chatterjee 2015). These studies provide insights into which individual, household, and urban characteristics correspond with a higher level of multimodality. Such findings may shed some light on the potential determinants of multimodality and may support policy efforts to reduce car dependency by increasing the use of a wider variety of transport modes. However, studies on the correlates of multimodality are often based on cross-sectional data, and as such, no causal relations can be drawn from them (see Scheiner et al. 2016 for an exception).

Only a limited number of studies have focussed on trends in multimodality (Kuhnimhof et al. 2011; Buehler and Hamre 2016; Kuhnimhof et al. 2012a, 2012b; Streit et al. 2015). The surveillance of trends over time is important to understand the incidence of multimodality, to understand whether multimodality is increasing or decreasing, and to reveal whether the distribution is changing. The monitoring of trends may as such reveal potential future problems.

Most studies to date suggest that car use is decreasing and-perhaps consequentlymultimodality is increasing. However, these studies are limited in several ways. The majority of the trend analyses are based on a limited number of years; some only report changes between two, or at most, 3 years, whereas others pool years together and report averages for periods. However, the data analysed are derived from sample surveys. As a result of changes in the survey design or survey collection or of changes in the sample variability, fluctuations in the measured behaviour may occur, and large travel surveys, such as the National Travel Survey (NTS) consequently put their users on guard not to draw conclusions from short-term changes (DfT 2015a). Comparing 2 years may therefore offer insufficient reliability on reported trends, as one may not be able to separate secular trends from irregular variations.

Second, the indicators of multimodality used in existing research on trends in multimodality do not correspond with recent advances in this field, e.g. Diana and Pirra (2016). In some studies, changes in other travel behaviour characteristics, such as aggregate 
measures including modal split or changes in the habitual frequency of certain mode, are sometimes interpreted as changes in multimodality. However, the measurement of multimodality is more complex and needs to take account of both the modal mix of transport modes used as well as the frequency that each mode is used. This relates to the third shortcoming in existing studies on trends in multimodality. Until now, limited attention has been paid to the relationship between various indicators of multimodality and trends in the use of different modes of transport, in particular car use, whereas it is often implied that an increase in multimodality corresponds with a reduction in car use. Given that multimodality may be seen as a potential first step away from 'habitual' car dependency, it is important to disentangle the relationship between car use and the level of multimodality.

Fourth, there is still limited evidence on how multimodality is distributed across society. For policy, it is important to know whether a decrease in car travel may be attributable to a large share of individuals with a reduced number of alternatives, i.e. less car access, or to individuals who have multiple alternatives but make deliberate choices to use public transport or active travel (Kuhnimhof et al. 2012a). Similarly, it is important to unravel whether differences between socio-economic groups in the level multimodality-the actual use of a variety of mode of transport - are stable or whether differences are growing or attenuating. For the aim to determine the predictors of multimodality, understanding the trends in multimodality by well-known correlates provides some insight into the relationship between them. From the standpoint of social equality, it is important to understand whether aggregated national trends are distributed similarly over the population or whether travel with a variety of modes is exclusively available for certain groups.

This study aims to advance the research on trends in multimodality, and the purpose of this study is to investigate long-term trends in multimodality in England with contemporary indicators of multimodality. In addition, it explores whether these trends are homogenous, i.e. whether they are similar between socio-economic characteristics and how trends in multimodality correspond with changes in car use and the use of other modes. For this, we analysed a national representative repeated cross-sectional survey, the NTS of England. The NTS allows us to describe patterns of how different transport modes are used and to monitor trends in travel to inform policy formulation. Additionally, it allows us to assess whether different socio-economic groups may be impacted by policies equally. A better understanding of existing trends and the prevalence of those in groups will not only allow us to understand the predictors of multimodality better, it also allows us to test often assumed consequences of the use of certain modes on multimodality, and as such, offers insights to reflect on current policy aims and efforts to make societies more multimodal to improve sustainability and quality of life.

\section{Background}

\section{Measuring multimodality}

There are two broad understandings of multimodality in the scientific and policy literature, although this distinction is not often explicitly made. In the first, 'aggregate' understanding, multimodality is seen as an attribute of a group or the population of a country or city. In this sense, a population is more multimodal if its (aggregate) modal split is not dominated by a single mode, but rather is characterised by a balance of different modes. This is quite distinct from the second understanding, which sees multimodality as an 
attribute of individuals and their travel patterns. This is the understanding of multimodality that is adopted in this paper.

Individual-level multimodality is characterised in two ways in the scientific literature. The first characterisation method is 'categorical', i.e. individuals are classed into different groups based on the variety of modes they use in a certain period. Most commonly, these groups are predefined. Examples of such groups are 'monomodal car users', 'multimodal car users', etc. (e.g. Nobis 2007; Buehler and Hamre 2015). Another method of grouping individuals, which is currently less commonly applied, comprises data-driven groups (Kroesen 2015; Molin et al. 2016). Categorical indicators allow to make statements on which modes are being used, but do not provide information on the level of variation in use. The second method of characterising multimodality is by continuous indicators, which measure the level of multimodality (e.g. Heinen and Chatterjee 2015; Susilo and Axhausen 2014). This method does not permit to make statements on which modes are used necessarily, which may be seen as a shortcoming of this method. Perhaps surprisingly, the variety in indicators may be larger for continuous indicators than for grouping. The most commonly applied indicators include variations of the Herfindahl-Hirschman index (e.g. Susilo and Axhausen 2014; Heinen and Chatterjee 2015; Scheiner et al. 2016). Diana and Pirra (2016) recently investigated several continuous indicators including Gini, Dalton, Atkinson, Entropy, and Herfindahl indices for their ability to correctly measure the level of multimodality. They concluded that none of the indicators outperformed any other indicator in the qualities they considered. However, they recommend the use of a variation of the Herfindahl-Hirschman index (HHm), as well as variations of the Shannon entropy and Dalton indices based on their properties to represent multimodality, the former three specifically "if the researcher could be interested in measuring the "real" multimodality behaviour by simply considering the number of travel means that the individual is using from a pre-defined set, irrespective of the fact that some of these are not accessible to some individuals' (p. 780). However, if the average use of different modes varies between respondents and some modes are hardly used, DALm appears the best index. However, as yet, there is no agreement on which indicator to use. One important aspect that has not been considered sufficiently in the scientific debate on which indicator is best, is the ease of interpretation. The trade-off between ease of interpretation and correctly measuring multimodality will require further exploration.

It is important to note that the measured level of multimodality as well as the division of individuals into groups depends on the characteristics of the data. Three elements are particularly important in this light: the duration of the period covered of the data collection, the number of modes considered, and the level on which the number of modes are considered. The number of days has been shown to have a large effect on whether an individual can be considered multimodal or not (e.g. Buehler and Hamre 2016). In general, the longer the measurement of travel behaviour, the more likely there is some variation in mode choice. Second, the number of modes considered is very important when evaluating whether an individual has used single or multiple modes. More aggregate groups of modes, such as active travel and public transport, may result in an underestimation of the variety of the modes used (see e.g. Heinen and Chatterjee 2015). Finally, multimodality can be investigated at a stage, trip or journey level. The effect of all these three aspects may differ dependent on the characterisation of multimodality. There is ongoing debate on which indicator is best used as a measure of multimodality, as well as over how many days should be considered and on which level it should be measured (Diana and Pirra 2016; Scheiner et al. 2016; Heinen and Chatterjee 2015). 


\section{Predictors of multimodality}

Over the past few years, various studies have investigated the predictors of multimodality (e.g. Nobis 2007; Buehler and Hamre 2015; Heinen and Chatterjee 2015). Broadly, it appears that multimodality is more prevalent among women and in areas with greater densities. Unimodal car users are, on average, more likely male, white, full-time employees, individuals with young children, and car owners. They are less often students. Age results appear to vary between countries. Older people show more multimodality in Germany, but greater age is associated with lower levels of multimodality in the USA and Great Britain (Heinen and Chatterjee 2015).

In addition, life events have been found to be associated with changes in multimodality (Scheiner et al. 2016). In the event that a child leaves their parental house, the level of parent multimodality increases. A similar relationship was found for leaving the labour market, whereas entering the labour market reduced the level of multimodality.

\section{Trends in multimodality}

The research on trends in multimodality is still relatively limited. This is likely due to the desired availability of repeated multi-day surveys, using identical methods. Kuhnimhof et al. (2011) investigated car availability, mode use, and multimodality in Germany and Great Britain, with a focus on individuals between 20 and 29 years of age. They used two datasets for Germany: 4 years from the Mobility in Germany [Mobilität in Deutschland (MiD)] $(1982,1989,2002,2007)$ and three time points from the German Mobility Panel (MOP) (1995-1999, 2000-2004, 2005-2009). For Great Britain, the National Travel Survey was used from 1996, 1999, 2002, and 2005. The authors implicitly adopted an aggregate understanding of multimodality and focussed on frequency of car and public transport use. They found an increase in the habitual frequency of public transport use (in the aggregate) for the group of young car owners, and concluded on this basis that multimodality has increased. At the same time, their analyses revealed that there was an aggregate reduction in miles driven by car. This may partly be explained by a reduction in car availability. These findings were more pronounced in Germany than in Great Britain.

Kuhnimhof et al. (2012a) investigated the trends in travel behaviour of young adults in six countries: Germany, France, Great Britain, Japan, Norway, and the USA. They compared a maximum of 3 years, one in the 1970s/1980s, one in the 1990s, and one after 2005, all depending on data availability within a specific country. Since 2000, car accessibility has decreased in most countries and this was more pronounced in men than women. Similarly, the average daily distance travelled by car has decreased in these countries. Interestingly, this reduction in car travel resulted in an overall decrease in travel in France, Japan, and the USA. However, in Great Britain and Germany, this decline in car travel was (partly) compensated by an increase in travel by other modes of transport.

Kuhnimhof et al. (2012b) analysed travel trends of young adults aged between 18 and 29 in Germany by use of the MOP. They compared 3 years: 1976, 1997, and 2007 and found that car access and car use declined for young adults in Germany. By comparing whether individuals used a car, public transport, or a bicycle either daily, weekly, monthly, or even less often, they concluded that multimodality among young adults had increased. Multimodality appeared to have specifically increased among those with car access.

Streit et al. (2015) used the MOP to investigate trends of variety of mode use, comparisons of daily trip chains, and variations of trip length. They compared two periods 
1998-2000 and 2010-2012, based on a bespoke continuous indicator of individual-level multimodality, and concluded that this had significantly increased among young adults. This trend could be observed in both genders.

Finally, Buehler and Hamre (2016) explored the changes in individual-level multimodality in the USA based on the National Household Survey from 2001 and 2009. They investigated multimodality on the levels of trip chains, days, and weeks. The first two were based on travel diaries, whereas the last was based on a one-day diary and self-reported frequency of use for commuting over the last week. They showed that monomodal car use on all levels had decreased between 2001 and 2009. The main increase was not in the multimodal car group-which increased in all level except in chained trips-but in the 'walking, bicycle, and/or public transportation-only' group, which was, however, the smallest group overall.

In conclusion, most studies that have investigated trends in multimodality reported that multimodality had increased. This increase may have been particularly strong among younger people with access to a car. However, all trends analyses were based on a limited number of years, sometimes only two. Comparing only a few years does not enable to separate the secular trends from irregular variations, which may possibly due to changes in the survey or data collection. The results are therefore not very reliable. Some existing studies were also based on an aggregate understanding of multimodality. Trends in the actual level of multimodality at the level of individual travel patterns, as well as the differences between groups have remained largely unexplored. Therefore, it remains questionable what the exact trends of multimodality are, and whether changes in these are equally distributed within societies. The latter is important for policy as a change towards more sustainable modes of transport by choice has different societal consequences than those reductions made due to economic or social restriction.

\section{Method}

\section{Data}

To analyse trends in multimodality, there are multiple data requirements. First, to measure multimodality, it is strongly recommended to have multiple-day travel diaries. Second, to investigate trends, it is necessary to have repeated collections of such multi-day travel diaries. These could either be a sample of the same individuals over multiple years, i.e. a panel, or a repeated cross-sectional survey, representative of a population.

We used the Great Britain National Travel Survey (NTS). The NTS is a cross-sectional survey that is conducted annually. The NTS is 'designed to monitor long-term trends in personal travel and to inform the development of policy' (DfT 2016a). The NTS is a representative household survey of Great Britain, although starting from 2013, the sample is limited to England alone. It was first conducted in 1965/1966 (Rofique et al. 2011) and has continued for every year since then.

To recruit individuals, households receive an advance letter to provide background of the survey, its importance and information on how the household was selected. After the first letter, interviewers make contact by a personal visit, and interviewers are required to make a minimum of six and a maximum of nine calls at different moments of the day and week. The survey is currently administered through face-to-face interviews with household members using Computer-Assisted Personal Interviewing. Each household member is 
requested to fill in a 7-day travel diary. Weighting was developed in 2005, and applied to data from 1995 onwards. The application of weighting has caused a change within the NTS data. We therefore analyse the trends from 1995 onwards.

The NTS has been a continuous survey since 1988, with an annual sample size of 5040 addresses, increasing to 5796 addresses by 2001, and set to 15,048 in 2002 . In 2015 , the NTS was based on a stratified, clustered random sample of 12,852 private households draw from a postcode file. In 2015, a national response of $61 \%$ was achieved (NatCen Social Research 2016).

Over the years several changes have been made, including the removal or adding of questions, or changes in the frequency that questions were asked. More substantial changes include the following:

- Data prior to 2002 are based on smaller annual sample sizes, which can result in less accurate estimates for single years (DfT 2015b).

- From 2002 onwards, NTS has introduces a quasi-panel design (NatCen Social Research 2016). This means that half of the primary sampling units (which correspond with postcode sectors) in a given year will be kept in the sample of next year, whilst half will be replaced.

- After this successful experiment in 2002 with offering an incentive, from 2003 onwards, households that fully participated are offered a $£ 5$ voucher.

- In 2007, the travel record was redesigned, and 'since 2014 interviewers have been provided with a list of key points to cover when placing a checking a travel diary' (NatCen Social Research 2016, p. 22).

- In 2013, several items of the interview and travel record were removed after a smaller redesign.

- In 2013, the data collection was limited to England.

- In 2013 and 2015, experiments were conducted with the collection of short walking trips. In NTS, short walking trips are only recorded on the last day of the 7-day survey (weighting is then applied), and in the two experimental years, a small proportion of the NTS sample were asked to report short walking trip on the first day. Given that large differences were observed in the recording of short walking trips, the travel diary data of the experimental sample were not included in the NTS data.

We followed Heinen and Chatterjee (2015) to prepare the data for analyses on multimodality. In short, we first used the 'stages file' in the NTS to calculate various multimodality indicators (see "Measurement of multimodality" section). We determined the number of stages, whilst applying weighting for short walks and drop-offs in reporting for eight categories of transport mode [NTS weight: SSXSC (short walk weight) and W5xHH (Trip/stage weight excluding household weight)]: walk, bicycle, car driver, car passenger, bus, rail, taxi, and other (motorcycle and other private and public transport). Similarly, we also determined the number of stages considering three modes of transport: car transport (car driver and car passenger), active travel (walking and cycling) and public transport (bus, rail, taxi, and other). Second, we added this information to the 'individual file' in NTS. Third, we calculated various indicators of multimodality for each individual (see "Measurement of multimodality" section). We applied the weighting available in NTS to adjust for non-responses, probability of selection, and to reproduce sample population characteristics [NTS weight: W2 (Diary sample household weight)]. 


\section{Measurement of multimodality}

To investigate whether the level of multimodality changed, we used continuous indicators of individual modal variability. Given that there was no one single best indicator, we explored various indicators based on existing studies on multimodality (e.g. Diana and Pirra 2016; Heinen and Chatterjee 2015; Susilo and Axhausen 2014; Streit et al. 2015). We considered indicators that were either widely used, shown to be mathematically superior to measure multimodality over other indicators, and indicators that were relatively easy to interpret. We calculated all multimodality indicators considering the eight modes (walk, bicycle, car driver, car passenger, bus, rail, taxi, and other), as well as for three modes (private transport, public transport, and active transport), similar to Heinen and Chatterjee (2015). The detailed formulae for these indices are available in the papers referenced below.

- The number of modes used.

- The difference in percentage of use between primary and secondary modes (Heinen and Chatterjee 2015).

- The Herfindahl-Hirschman Index (HHI) as applied by Heinen and Chatterjee (2015), and a variant, HHm, based on Diana and Pirra (2016).

- An index based on the Shannon Entropy, based on Diana and Pirra (2016) OM_PI.

- The Dalton Index, based on Diana and Pirra (2016) DALm. ${ }^{1}$

- The Multimodal indicator (MM), based on Streit et al. (2015).

The first two measures can be easily interpreted, whereas the HHI is a commonly applied measure. The HHm, OM_PI and DALm are among the indicators recommended by Diana and Pirra. HHm and OM_PI are particular appropriate when considering a set number of travel means, independent on whether an individuals has access to it (Diana and Pirra 2016). However, if some considered modes are hardly used, which is likely when you consider a large number of modes, DALm seems best, since other indices are more scale invariant (Diana and Pirra 2016). The MM has been proposed in one of the few studies showing changes over time in multimodality based on a continuous indicator (Streit et al. 2015).

For the interpretation, it is important to note that three of the measures (number of modes, OM_PI, MM) are indices of variability. Thus, a higher value means a higher level of variability in mode use, i.e. greater multimodality. The other four measures (difference between primary and secondary mode, HHI, HHm, DALm) are indices of concentration. Thus, a higher value means a greater concentration of stages among a few modes, i.e. less multimodality. We calculated measures for multimodality indicators for every year from 1995 until 2015.

\section{Analyses}

In this paper, we investigated the trends in multimodality from 1995 onwards. The years before 1995 were not analysed as NTS data have only been weighted from 1995 onwards, which has caused a one-off uplift in trips and distance travelled between 1992/1994 and 1995/1997 (DfT 2016b). Our analyses were restricted to adults (aged 16 years and over),

\footnotetext{
1 In order to compute DALm, an inequality aversion parameter $\varepsilon$ needs to be set at a specified value. Following Diana and Pirra (2016), we set $\varepsilon$ at 0.5 in order to maximise the sensitivity of the index (p. 785).
} 
similar to Heinen and Chatterjee (2015). In order to ensure a consistent time series throughout the period, our analysis refers to residents of England alone.

The first analyses focus on the exploration of the trends in the level of multimodality between 1995 and 2015 for the indicators listed in "Measurement of multimodality" section. We visualised the trends in multimodality. The values presented by year are (weighted) mean values of the population. We smoothed the trend lines by showing the centred moving average of three consecutive years (or 2 years for first and last year in the trend analyses). Similarly, we explored the trends in multimodality by different characteristics that have been revealed as correlates of multimodality. For all trend analyses, we looked both at the trends for three and eight modes.

Given that some multimodality indicators may be affected by the number of stages or trips, we tested whether the level of multimodality was correlated with the number of stages. Our exploration showed that the correlation between unweighted number of stages and the indicators was low (between 0.10 and 0.20 for indicators considering three modes, and between 0.15 and 0.31 for indicators considering eight modes). The correlations for the weighted number of stages and the indicators were slightly higher, but still only moderate (between 0.26 and 0.40 ). The exclusion of individuals with less than eight stages showed less strong correlations. We therefore conducted the analyses on all individuals with a travel diary, but we conducted sensitivity analyses excluding individuals that recorded fewer than eight stages in the diary week, as these individuals could never be considered fully multimodal given the consideration of eight different modes of transport.

Second, we estimated a multivariate model to test the correlates of multimodality and whether these have changed over time. We followed Heinen and Chatterjee (2015) and estimated the correlates of multimodality on HHI for three and eight modes, using a fractional logit model which entails a logit transformation of the response variable, given the distribution of the dependent variable. These models have been developed for estimating models with a proportion as a dependent variable, with values ranging from zero to one, including zero and one (Papke and Wooldridge 1996). We combined the years 2002-2015 into one dataset to allow to investigate changes in multimodality over time. We only applied the weighting available for short walking trips and trip/stage weight excluding household weight. We limited our analyses to the years 2002-2015, given that some independent variables did not have consistent indicators between 1995 and 2015. We considered the following independent variables (Table 1): year of survey, age, gender, ethnicity, urban/rural status, car ownership, income, whether an individual was working from home, whether an individual was working at multiple locations, the presence of children in household, bicycle accessibility, difficulty with walking, housing typology, housing tenure, having a public transport ticket, and economic status. Moreover, we explored the interaction effects between the year of survey and socio-economic characteristics that were shown to be either diverging or converging in the explorations of trends, to investigate whether these observations were corroborated when controlling for other predictors of multimodality. We only included variables in the multivariate model that had a $P<0.25$ in the unadjusted models, and interaction effects only if they were significant in the unadjusted models. In addition we conducted four sensitivity analyses: (s1) the maximally adjusted model limited to individuals with 7 stages or more; (s2) the maximally adjusted model with the number of stages included; (s3) a maximally adjusted model with the number of modes used as a dependent variable; and (s4) a maximally adjusted model with OM_PI as a dependent variable. 
Table 1 Overview of variables in multivariate analyses*

\begin{tabular}{|c|c|c|c|c|}
\hline Variable & Category & $\mathrm{n}$ & $\%$ & $\begin{array}{l}\text { Number of modes } \\
\text { (considering } 8 \text { modes) }\end{array}$ \\
\hline \multirow[t]{3}{*}{ Age } & $16-30$ & 100,544 & 57.46 & 2.42 \\
\hline & $31-64$ & 35,676 & 20.39 & 2.21 \\
\hline & over 65 & 38,765 & 22.15 & 2.00 \\
\hline \multirow[t]{2}{*}{ Gender } & Male & 83,097 & 47.49 & 2.11 \\
\hline & Female & 91,888 & 52.51 & 2.29 \\
\hline \multirow[t]{5}{*}{ Income quintile } & Lowest & 30,544 & 18.72 & 2.07 \\
\hline & 2nd quintile & 30,994 & 19.01 & 2.09 \\
\hline & 3rd quintile & 32,315 & 19.83 & 2.17 \\
\hline & 4th quintile & 34,886 & 21.40 & 2.25 \\
\hline & Highest & 34,262 & 21.02 & 2.44 \\
\hline \multirow[t]{3}{*}{ Ethnicity } & White & 158,814 & 90.81 & 2.21 \\
\hline & Asian & 8571 & 4.90 & 2.02 \\
\hline & Other & 7495 & 4.29 & 2.25 \\
\hline \multirow[t]{6}{*}{ Settlement size } & Inner London & 8978 & 5.13 & 2.64 \\
\hline & Outer London & 19,606 & 11.20 & 2.42 \\
\hline & Other Metropolitan areas & 26,205 & 14.98 & 2.19 \\
\hline & Large urban & 44,582 & 25.48 & 2.19 \\
\hline & Small urban & 53,331 & 30.48 & 2.14 \\
\hline & Rural & 22,283 & 12.73 & 2.04 \\
\hline \multirow{3}{*}{$\begin{array}{l}\text { Number of cars in the } \\
\text { household }\end{array}$} & None & 70,720 & 40.42 & 2.19 \\
\hline & 1 car & 31,145 & 17.80 & 2.30 \\
\hline & 2 or more cars & 73,119 & 41.79 & 2.18 \\
\hline \multirow[t]{2}{*}{ Working from home } & No & 97,466 & 95.68 & 2.27 \\
\hline & Yes & 4398 & 4.32 & 2.23 \\
\hline \multirow{2}{*}{$\begin{array}{l}\text { Working at multiple } \\
\text { locations }\end{array}$} & No & 80,486 & 95.68 & 2.28 \\
\hline & Yes & 21,378 & 4.32 & 2.23 \\
\hline \multirow{2}{*}{$\begin{array}{l}\text { Having child(ren) in the } \\
\text { household }\end{array}$} & No & 121,252 & 69.29 & 2.19 \\
\hline & Yes & 53,733 & 30.71 & 2.25 \\
\hline \multirow[t]{2}{*}{ Bicycle accessibility } & No & 108,878 & 62.25 & 2.09 \\
\hline & Yes & 66,036 & 37.75 & 2.37 \\
\hline \multirow{2}{*}{$\begin{array}{l}\text { Having difficulty } \\
\text { walking }\end{array}$} & No & 155,151 & 88.70 & 2.25 \\
\hline & Yes & 19,767 & 11.30 & 2.06 \\
\hline \multirow[t]{3}{*}{ Housing typology } & Detached & 46,715 & 26.70 & 2.19 \\
\hline & Semi-detached or terraced & 106,361 & 60.78 & 2.18 \\
\hline & Flat or other & 21,908 & 12.52 & 2.31 \\
\hline \multirow[t]{2}{*}{ Housing tenure } & Own & 128,074 & 73.28 & 2.14 \\
\hline & Rent or other & 46,705 & 26.72 & 2.22 \\
\hline \multirow{4}{*}{$\begin{array}{l}\text { Having a public } \\
\text { transport ticket }\end{array}$} & None & 119,314 & 68.52 & 2.20 \\
\hline & $\begin{array}{l}\text { Old age pensioner (OAP) } \\
\text { with bus pass }\end{array}$ & 35,428 & 20.34 & 3.04 \\
\hline & Season ticket & 9554 & 5.49 & 2.58 \\
\hline & Other & 9842 & 5.65 & 2.11 \\
\hline
\end{tabular}


Table 1 continued

\begin{tabular}{lllll}
\hline Variable & Category & $\mathrm{n}$ & $\%$ & $\begin{array}{l}\text { Number of modes } \\
\text { (considering 8 modes) }\end{array}$ \\
\hline Economic status & Full time working & 75,998 & 43.43 & 2.22 \\
& Part time working & 26,103 & 14.92 & 2.40 \\
& Other & 24,476 & 13.99 & 2.29 \\
& Retired & 48,408 & 27.66 & 2.02 \\
\hline
\end{tabular}

* Combined NTS data from 2002-2015

\section{Results}

\section{Trends in multimodality}

The first step was the exploration of the trends in the level of multimodality between 1995 and 2015 for the indicators listed in "Measurement of multimodality" section (Figs. 1, 2).

Figures 1 and 2 show that as opposed to previous scientific papers, multimodality in England did not increase. In contrast, the level of multimodality in 2015 was lower than that in 1995. Although the smoothed lines still show some year-on-year fluctuations, a steady trend towards lower levels of multimodality is clearly apparent, with decreases for the indices of variability and increases for indices of concentration. Figures 1 and 2 also show that the patterns for most indicators were relatively similar. Moreover, the trends were nearly identical in all sensitivity tests-excluding individuals with fewer than eight stages (not reported). Upon closer inspection, it appears that between 2009 and 2010, and between 2000 and 2001, a decrease in multimodality took place. These do not correspond to any of the survey design changes reviewed in "Data" section. We are not aware of any other changes in data collection or weighting that could explain these drops.

Regardless of the number of modes considered, we observe fairly similar trends. An examination of the trends of multimodality measured considering the three modes revealed that multimodality decreased over time (Fig. 1). In 1995, the average number of modes used was 1.78 , which slightly decreased to 1.72 modes per week in 2015 . In addition, the reliance on a single mode increased. The difference between the level of use of the primary and secondary mode increased from approximately 67-69\% between 1995 and 2015.

The trends of the multimodality measures for eight modes showed fairly similar patterns (Fig. 2). For example, the number of modes used decreased on average from 2.26 in 1995 to 2.17 in 2015 and the difference in use between the primary and secondary mode increased slightly from 59 to $60 \%$.

\section{Trends in multimodality for different groups}

The second part of the analyses in this paper focuses on trends in multimodality by different characteristics that have been revealed as correlates of multimodality. This stratification by socio-economic characteristics may reveal differences and inequalities regarding the (trends in the) level of multimodality. Given the similarities in trends among the indicators, we discuss the trends for the indicator 'number of modes' considering three and eight modes, which were the most intuitive indicators to interpret. All trends have been 


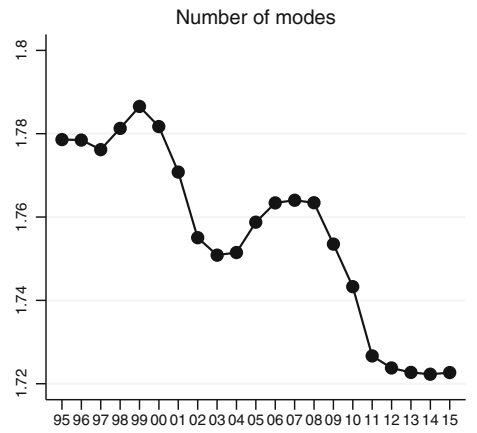

OM_PI
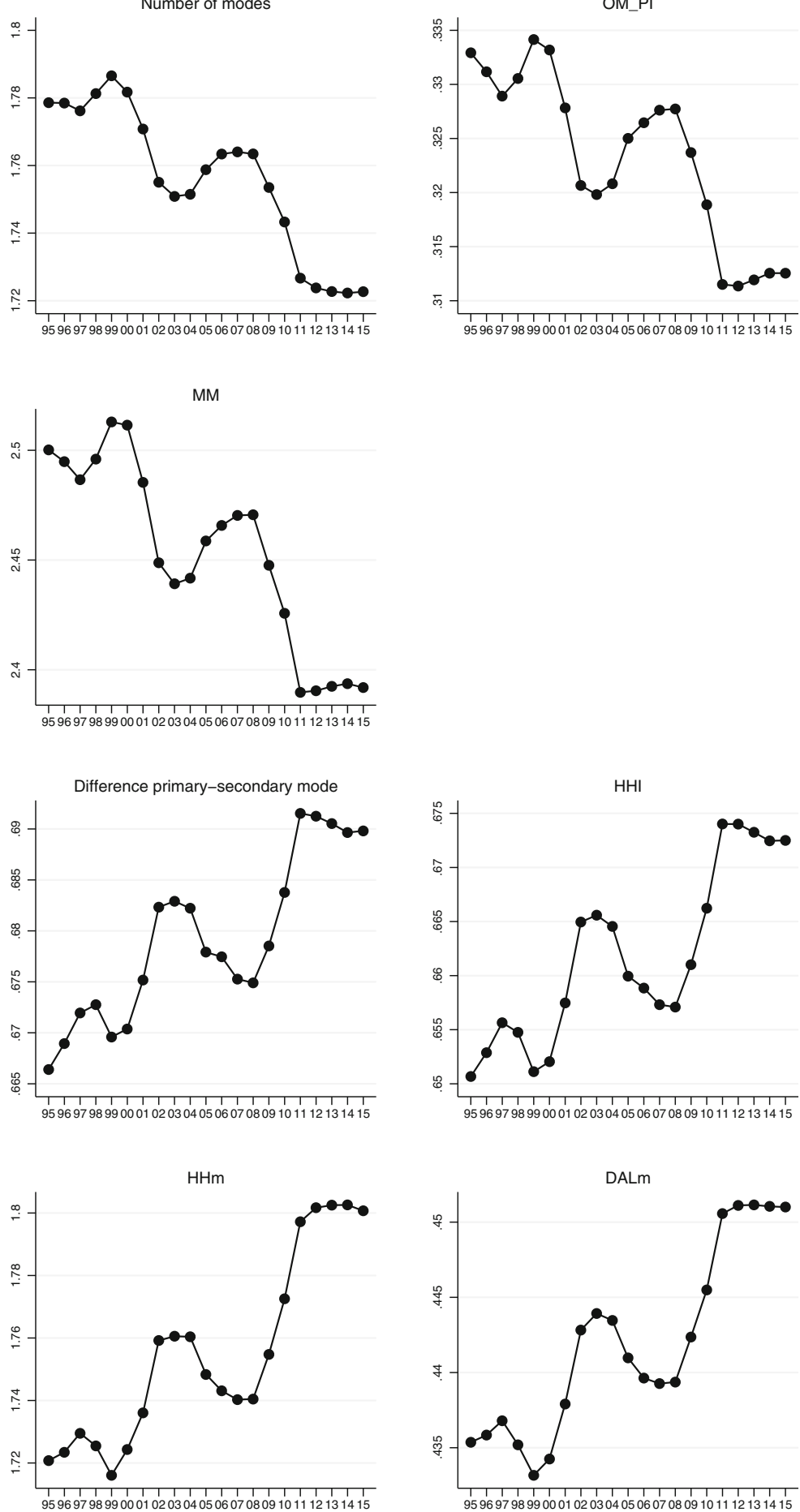
4Fig. 1 Trends in multimodality (measured considering 3 modes) 1995-2015. Note Sample size was 5086 in 1995, 12,955 in 2005, and 11,937 in 2015. The lines are smoothed, i.e. each point represent the centred moving average of three consecutive years. For the interpretation it is important to note that three of the measures (number of modes, OM_PI, MM) are indices of variability (upper half of Fig. 2). Thus, a higher value means a higher level of variability in mode use, i.e. greater multimodality. The other four measures (difference between primary and secondary mode, HHI, HHm, DALm) are indices of concentration (lower half of Fig. 2). Thus, a higher value means a greater concentration of stages among a few modes, i.e. less multimodality

checked for consistency against the other indicators reported in Figs. 1 and 2 (graphs not reported here for the sake of brevity).

\section{Gender}

Figure 3 shows the trends in multimodality by gender. Women were, on average, more multimodal than men, but the trend analysis indicated that the levels were converging. In 1995, men used, on average, 2.16 modes (1.72 for the three-mode indicator), whereas women used 2.35 modes (1.83 for the three-mode indicator). The level for men in 2015 was fairly similar as in 1995 despite fluctuations over time, approximately 2.08 modes (1.68 for the three-mode indicator), whereas women had, on average, reduced their number of modes by virtually $0.1-2.26$ modes per week (1.75 for the three-mode indicator).

This decrease may seem small, but it is quite substantial. To illustrate this, let us assume a sample of 200 individuals, 100 using two modes a week and 100 using three modes a week. This would result in an average of 2.5 modes per week. To reduce this by 0.1 mode, $20 \%$ of this sample would need to reduce the number of modes used by one mode per week.

Age

Age (Fig. 4) appeared to be strongly associated with the level of multimodality. On average, younger individuals (16-30 years) were much more multimodal, although over time, the level of multimodality appeared to be slowly converging. The average number of modes used by individuals between 16 and 30 years of age was, considering the indicator for three modes, approximately 1.93 modes in 1995, which decreased to 1.81 in 2015 . The number of modes for individuals between 31 and 64 years of age and over 65 years of age was fairly similar and stable over time, fluctuating around approximately 1.7 modes per week.

Looking at the indicator for eight modes (Fig. 4b), a different picture emerged. Age was still negatively correlated with multimodality, i.e. the younger the more multimodal, but the difference in age was now also present between the two older age groups. In 1995, the average number of modes used by individuals between 16 and 30 years of age, between 31 and 64 years of and over 65 years of age were 2.54, 2.24, and 1.91, respectively. In 2015, the levels of multimodality converged towards the level of the 31-to-64-year-old cohortfor individuals between 16 and 30 years of age: 2.27; individuals between 31 and 64 years of age: 2.18; individuals over 65 years of age: 2.04. The decrease in multimodality of individuals between 16 and 30 years of age was more pronounced than the increase of the oldest cohort. 

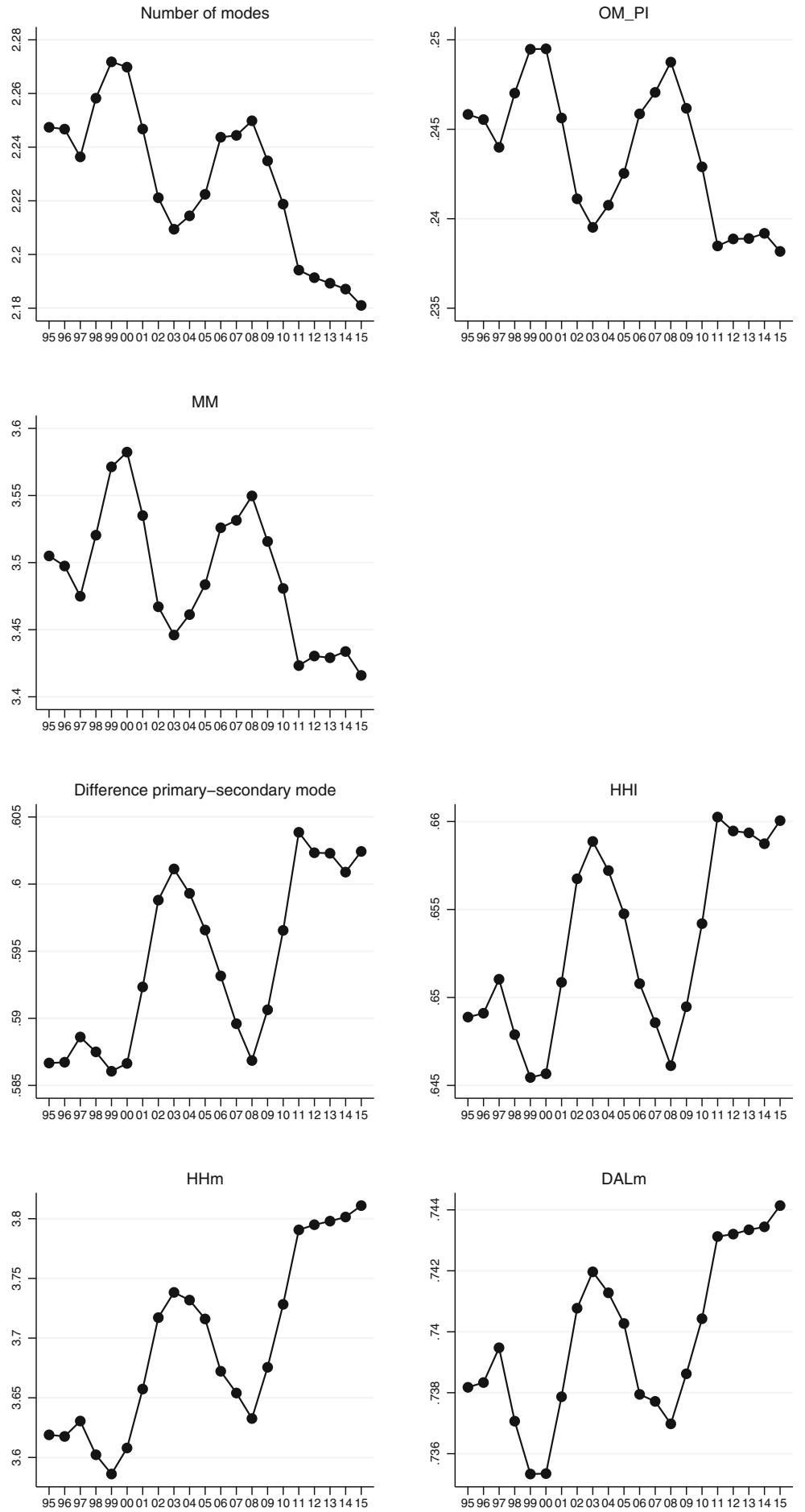
TFig. 2 Trends in multimodality (measured considering 8 modes) 1995-2015. Note Sample size was 5086 in $1995,12,955$ in 2005, and 11,937 in 2015. The lines are smoothed, i.e. each point represent the centred moving average of three consecutive years. For the interpretation it is important to note that three of the measures (number of modes, OM_PI, MM) are indices of variability (upper half of Fig. 2). Thus, a higher value means a higher level of variability in mode use, i.e. greater multimodality. The other four measures (difference between primary and secondary mode, HHI, HHm, DALm) are indices of concentration (lower half of Fig. 2). Thus, a higher value means a greater concentration of stages among a few modes, i.e. less multimodality

\section{Gender}

(a) Number of modes - 3 modes

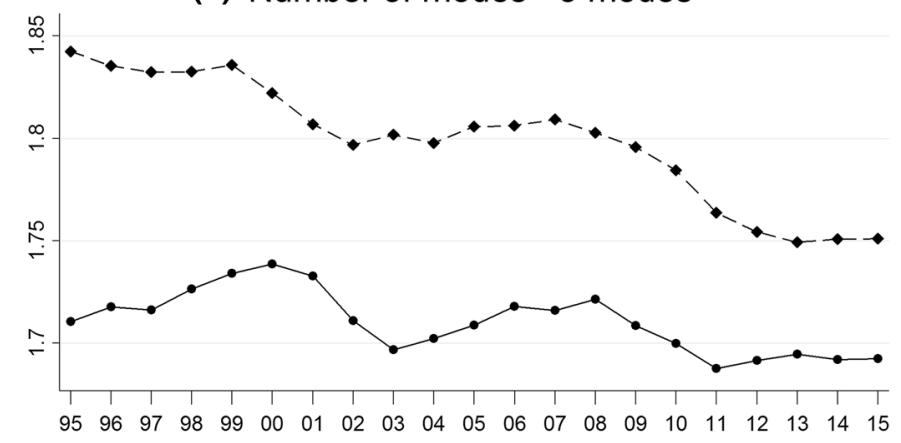

(b) Number of modes - 8 modes
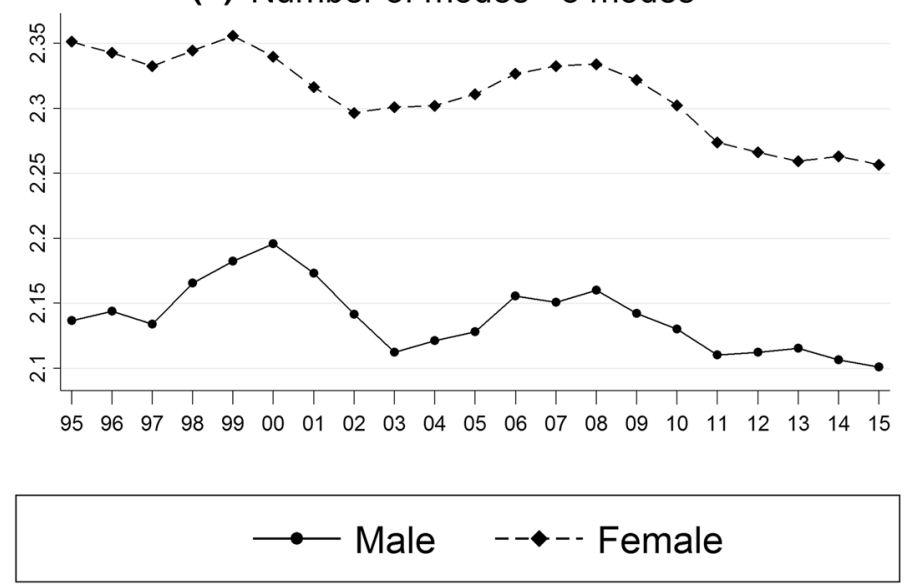

Fig. 3 Trends in multimodality by gender 1995-2015. Note Sample sizes were 2391 males and 2695 females in 1995, 6134 males and 6821 females in 2005, and 5861 males and 6256 females in 2015. The lines are smoothed, i.e. each point represent the centred moving average of three consecutive years

\section{Ethnicity}

Third, we investigated the differences in the level of multimodality by ethnicity (Fig. 5). This information was only available after 2001 in a comparable format.

Over time, the differences between ethnic groups increased. In addition, the exploration showed that the level of multimodality was lower among individuals of Asian ethnicity than individuals of white ethnicity. The levels of multimodality of other ethnic groups were less 


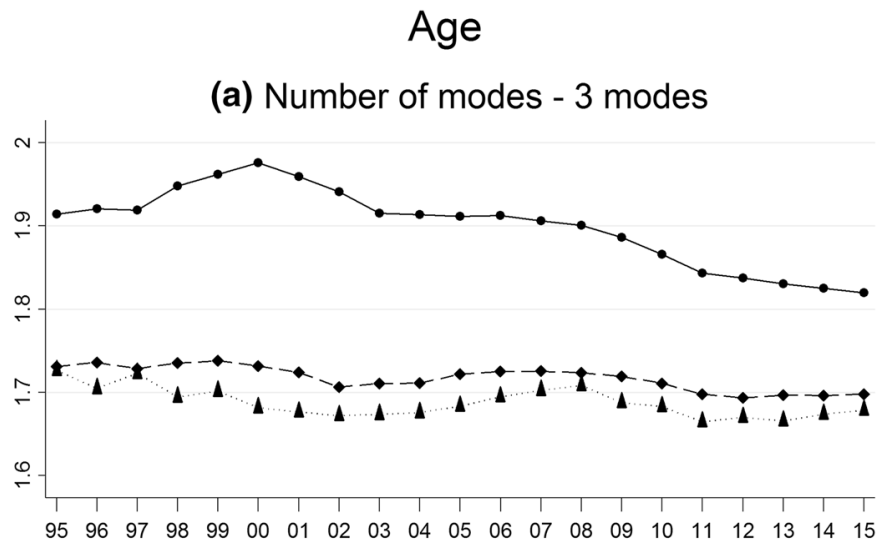

(b) Number of modes - 8 modes

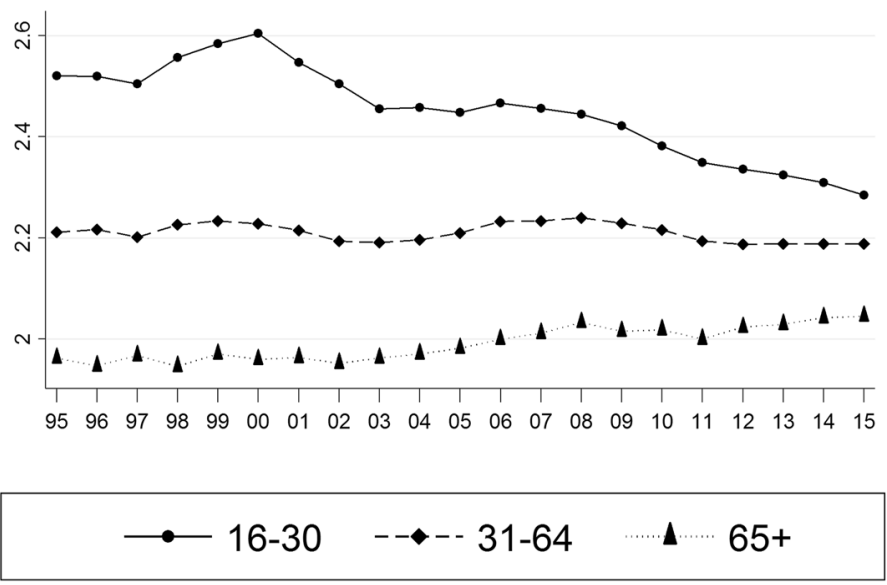

Fig. 4 Trends in multimodality by age 1995-2015. Note Sample sizes were 1236 individuals aged between 16 and 30 years, 2905 individuals aged between 31 and 64 years, and 945 individuals aged over 65 years in 1995; 2623 individuals aged between 16 and 30 years, 7573 individuals aged between 31 and 64 years, and 2759 individuals aged over 65 years in 2005; and 2363 individuals aged between 16 and 30 years, 6567 individuals aged between 31 and 64 years, and 3007 individuals aged over 65 years in 2015. The lines are smoothed, i.e. each point represents the centred moving average of three consecutive years

stable, which may be a result of the limited number of individuals in NTS having such backgrounds, and consequent large changes in the level of multimodality by variations in the sample.

\section{Income}

Our analyses revealed the existence of large differences between the highest income quintile and the other four quintiles (Fig. 6). Individuals within the highest (fifth) quintile were using 0.15 modes per week more than individuals in the other four groups in 2015 . Moreover, and in particular for the measures for three modes (Fig. 6a), the difference between the highest quintile and the other four quintiles increased over time, in particular 


\section{Ethnic group}

(a) Number of modes - 3 modes

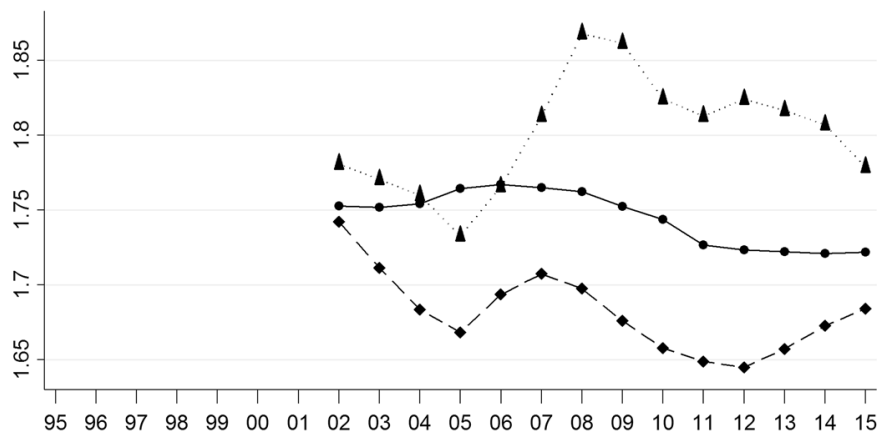

(b) Number of modes - 8 modes
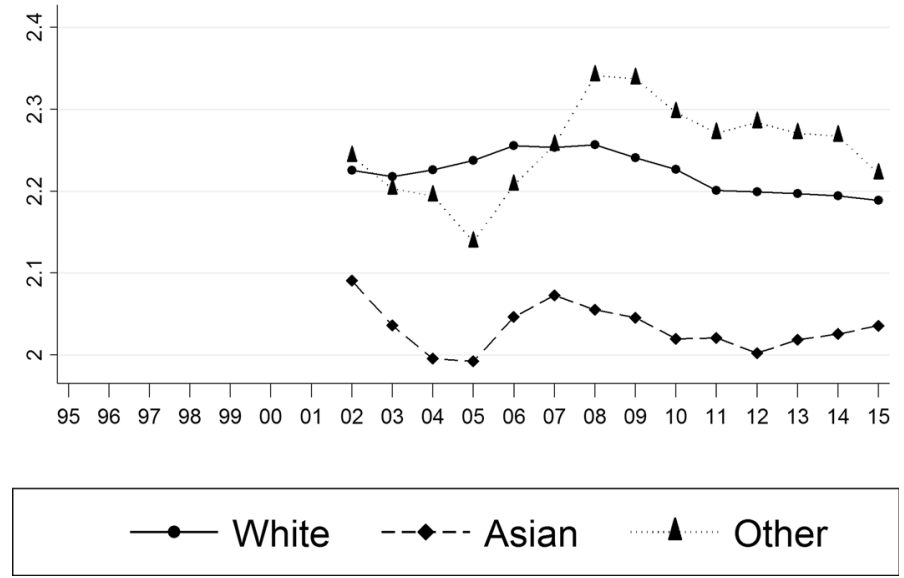

Fig. 5 Trends in multimodality by ethnicity 2001-2015. Note Sample sizes comprised 10,283 white individuals, 402 Asian individuals, and 349 individuals of other ethnicities in 2002; and 10,610 white individuals, 732 Asian individuals, and 589 individuals of other ethnicities in 2015. The lines are smoothed, i.e. each point represent the centred moving average of three consecutive years

due to all but the highest income quintiles decreasing their level of multimodality. Notably, when considering three modes only, the lowest income quintile shows a remarkable decrease, from levels comparable to the highest quintile in 1995 to some of the lowest levels of multimodality of all income groups in 2015 .

\section{Urbanisation}

Corresponding with existing studies on the correlates of multimodality, our analyses on urban/rural status (Fig. 7) showed that the more urban an area was, the more multimodal its inhabitants were. The difference in the number of modes used between inner London and rural areas differed by approximately 0.4 if considering three modes, and in excess of 0.5 when considering eight modes. London also differed clearly from all other areas when 


\section{Income quintile}

(a) Number of modes - 3 modes

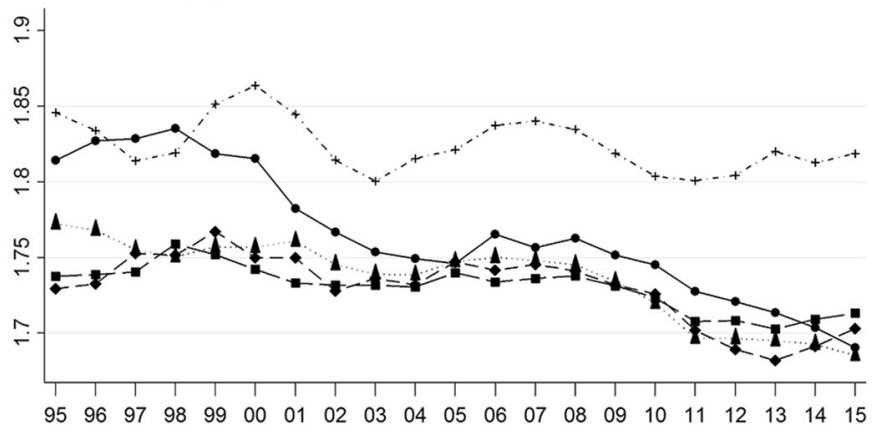

(b) Number of modes - 8 modes

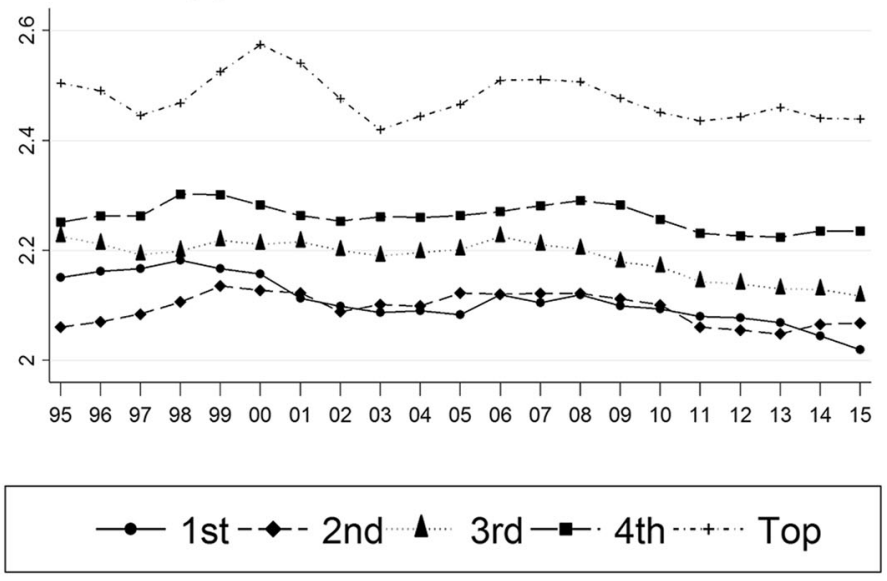

Fig. 6 Trends in multimodality by income quintiles 2001-2015. Note Sample sizes were 2054 individuals in the bottom quintile and 2024 individuals in the top quintile in 2002, and were 2182 individuals in the bottom quintile and 2504 individuals in the top quintile in 2015. The lines are smoothed, i.e. each point represent the centred moving average of three consecutive years

looking at eight modes. The other metropolitan areas in England (such as Manchester and Leeds) show larger similarities with smaller towns and rural areas than with London. Although there were some fluctuations over time, the level of multimodality stratified by urbanisation was fairly stable.

\section{Car ownership and access}

The final stratification was by car ownership. For this, we analysed the number of vehicles in the household. Note that car ownership in the NTS was defined on a household level, whereas our analyses were conducted on an individual level.

Trends in the levels of multimodality by car ownership (Fig. 8) showed that having fewer cars in the household was associated with higher levels of multimodality. Households without 


\section{Urban/rural status}

\section{(a) Number of modes - 3 modes}

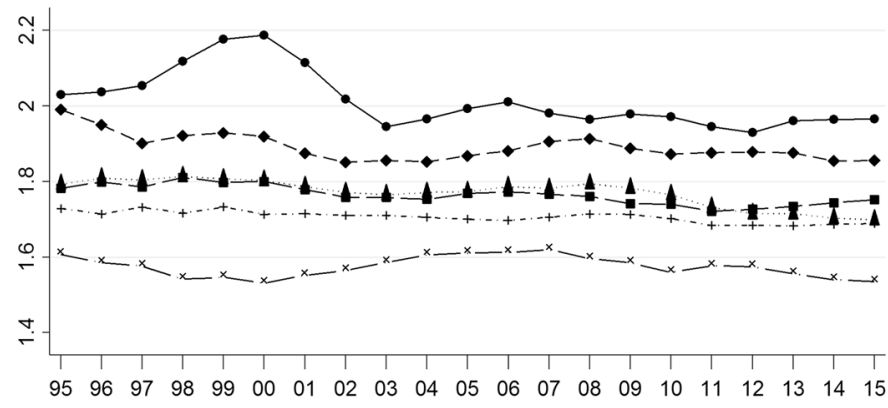

(b) Number of modes - 8 modes
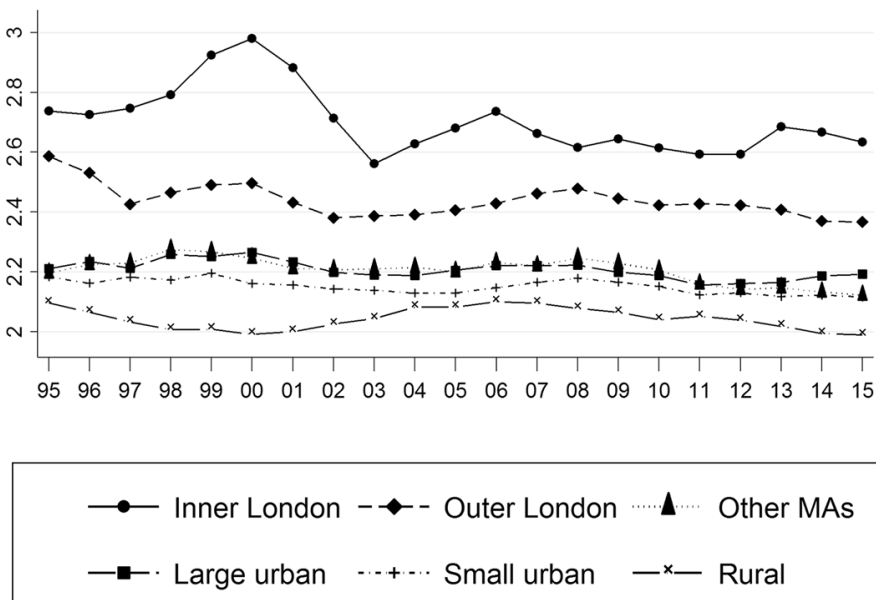

Fig. 7 Trends in multimodality by urban/rural status 1995-2015. Note Sample sizes were 261 individuals living in Inner London, 433 in Outer London, 671 in other metropolitan areas, 1431 in large urban areas, 1732 in small urban areas, and 556 in rural areas in 1995; 556 individuals living in Inner London, 1422 in Outer London, 1929 in other metropolitan areas, 3621 in large urban areas, 3924 in small urban areas, and 1481 in rural areas in 2005; 641 individuals living in Inner London, 1489 in Outer London, 1642 in other metropolitan areas, 3266 in large urban areas, 3283 in small urban areas, and 1616 in rural areas in 2015. The lines are smoothed, i.e. each point represent the average value of three years

cars had the highest levels of multimodality but these have been converging towards those of households with one car, notably for the eight-mode indicator. One should note that car ownership and the level of urbanisation are closely related in Britain (Mattioli 2014).

\section{Trends in unimodality}

The previous two sections showed that in contrast with previously reported trends in multimodality, the level of multimodality has decreased between 1995 and 2015. This decrease raises the question whether individuals have reduced the number of modes used and the frequency that they use them, or whether the decrease in the level of multimodality 


\section{Car ownership}

(a) Number of modes - 3 modes

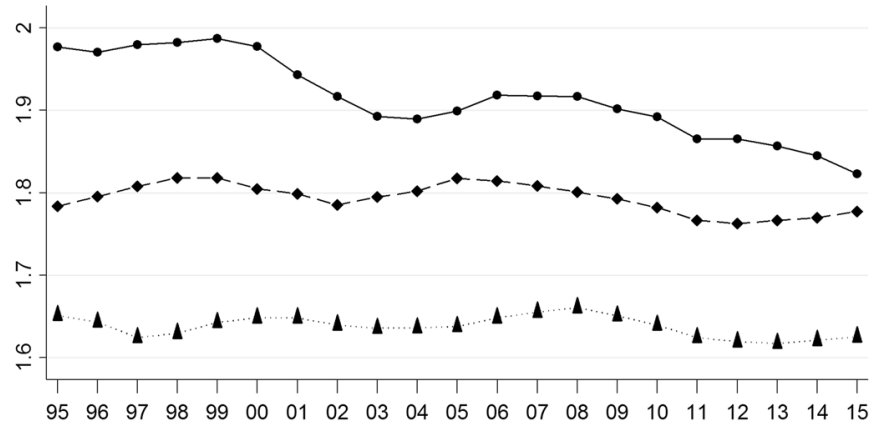

(b) Number of modes - 8 modes

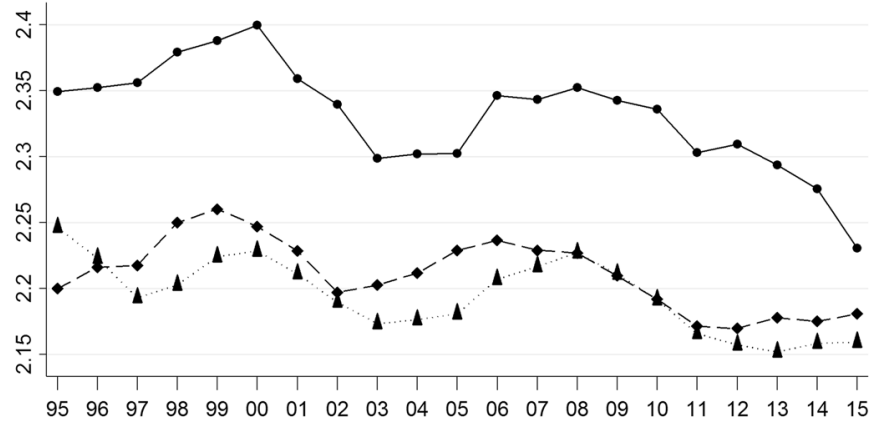

$\longrightarrow$ No car $\quad---1$ car $\quad . . . . \ldots 2+$ cars

Fig. 8 Trends in multimodality by car ownership 1995-2015. Note Sample sizes were 1132 individuals with no car, 2243 with 1 car, and 1711 with two or more cars in the household in 1995; 2282 individuals with no car, 5351 with 1 car, and 5322 with two or more cars in the household in 2005; and 2052 individuals with no car, 4943 with 1 car, and 4942 with two or more cars in the household in 2015. The lines are smoothed, i.e. each point represent the centred moving average of three consecutive years

also coincides with an increase in unimodality, the use of only one mode over the time frame-in this case one week.

Figure 9 shows the trends in unimodality, with stacked bars representing the proportion of unimodal individuals according to different modes. The share of unimodality increased between 1995 and 2015. Unimodality considering three modes (Fig. 9a) increased from 41 to $45 \%$ of the British population, and considering eight modes (Fig. 9b) there was an increase from 28 to $32 \%$ of the British population being unimodal. The decrease in the level of multimodality therefore appeared to have coincided with an increase in unimodality. Further explorations showed that the majority of unimodal only used the car (and no other mode). The absolute increase in unimodality was also mainly a result of individuals who only used the car, although, in relative terms, the increase was equally attributable to all modes. 

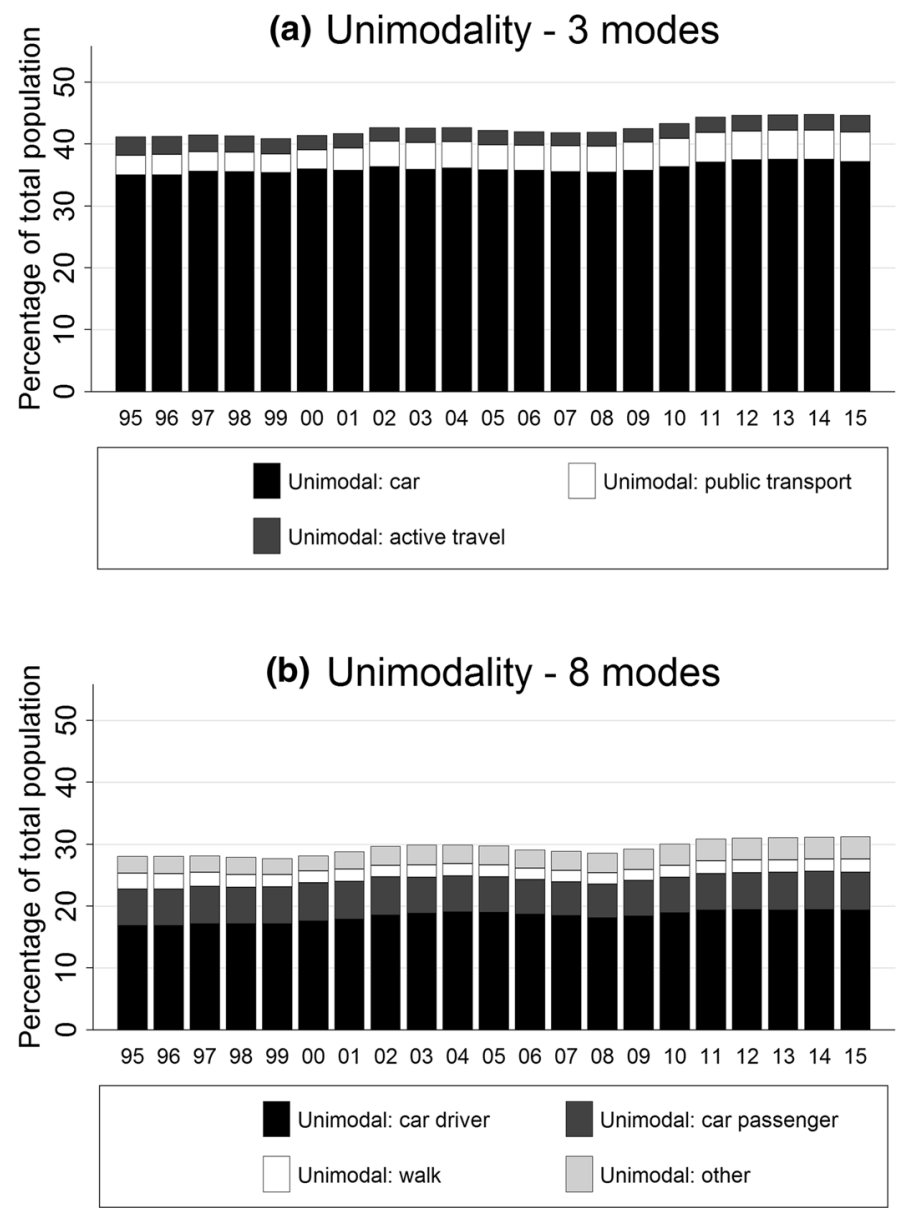

Fig. 9 Trends in unimodality 1995-2015. Note Sample sizes were 5086 individuals in 1995, 12,955 in 2005, and 11,937 in 2015. The trends are smoothed, i.e. each point represents the centred moving average of three consecutive years. In panel (b), 'Unimodal: other' is a residual category including individuals who use only one among bicycle, bus, rail, taxi, and other

\section{Trends in mode choice}

Given that policy has focussed on encouraging a partial shift away from the car, this section reports trends in car use and the use of other modes. We investigated four trends in mode use. First, we explored the trip rates based on the trip dataset. Consistent with the NTS definition of trip rates, we only considered the main mode of transport. Second, we considered travel distance by mode per capita-defined here based on stages travelled consistently with the NTS definition of distance per capita. The other two trends referred to the modal share. We considered mode shares based on the number of stages rather than trips, which deviates from the NTS methodology but appeared to be more appropriate given that the multimodality indicators were determined on stages, as well as the mode shares based on stage distance.

Figure 10 presents these trends in England between 1995 and 2015. In absolute terms, car use decreased, both in terms of trips (Fig. 10a) and distance (Fig. 10b). In contrast to 
(a) Trip rates

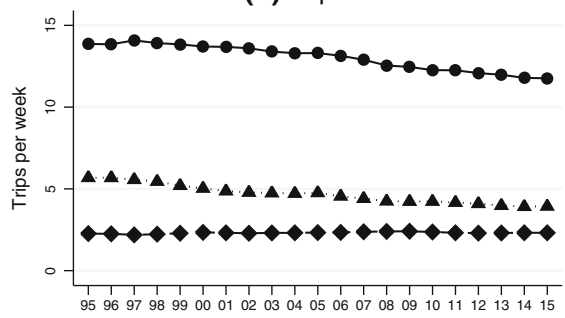

(c) Modal share (based on no. of stages)

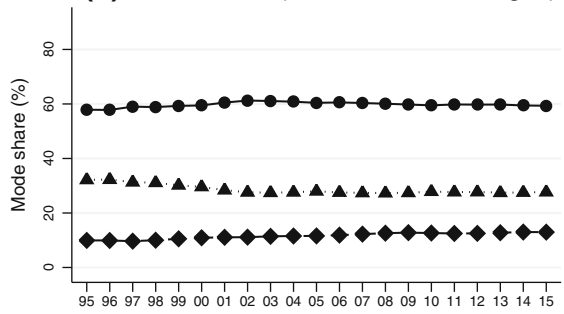

(b) Travel distance

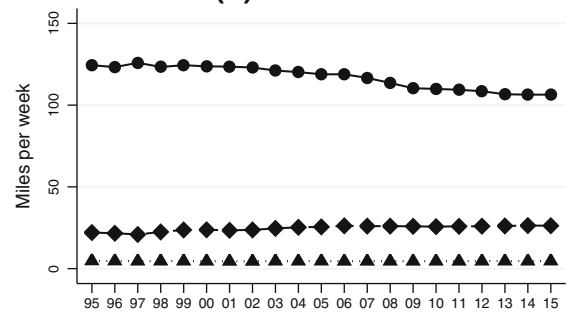

(d) Modal share (based on stage distance)

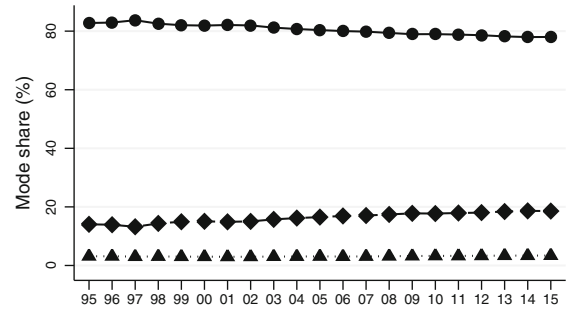

\section{$\longrightarrow$ Car $\longrightarrow-\bullet-$ - Public transport $\ldots \ldots \ldots \ldots$ Active travel}

Fig. 10 Trends in car use, bicycle use, public transport use and walking 1995-2015. Note Sample sizes were 5309 individuals in 1995, 13,416 in 2005, and 12,432 in 2015. The lines are smoothed, i.e. each point represent the centred moving average of three consecutive years

the absolute car use, the car modal share remained fairly stable, but increased a little over time. Whereas in 1995, 57\% of all stages were made by car, by 2015, this percentage increased to $59 \%$ ((Fig. 10c). The percentage of stages travelled by car mainly increased between 1995 and 2002, and slightly decreased thereafter. The trip rates and modal share of active transport decreased over the same period, but the distance travelled increased. The number of trips and mode share of public transport increased.

\section{Multivariate analyses}

The previous analyses showed that the trends in multimodality converged between age categories, gender and car ownership, whereas they diverged between income segments and ethnic groups. To test whether the observed trends were independent, we estimated fractional logit models to control for other variables. Unlike in Figs. 3, 4, 5, 6, 7 and 8, the dependent variable is the HHI index (for three and eight modes). We do this in order to maintain comparability with Heinen and Chatterjee (2015), who present findings from a similar regression model for 2010. The reader should note that, since HHI is an index of concentration, positive coefficients indicate a negative relationship between the predictor and levels of multimodality. We have also estimated models to predict the 'number of modes' and 'OM_PI' (See “Appendix 1”).

Table 2 presents the results of four models. We did not include interaction terms between year and ethnicity and car ownership in our maximally adjusted models. Ethnicity showed a significant interaction effect for the 'other' category in the unadjusted model. 


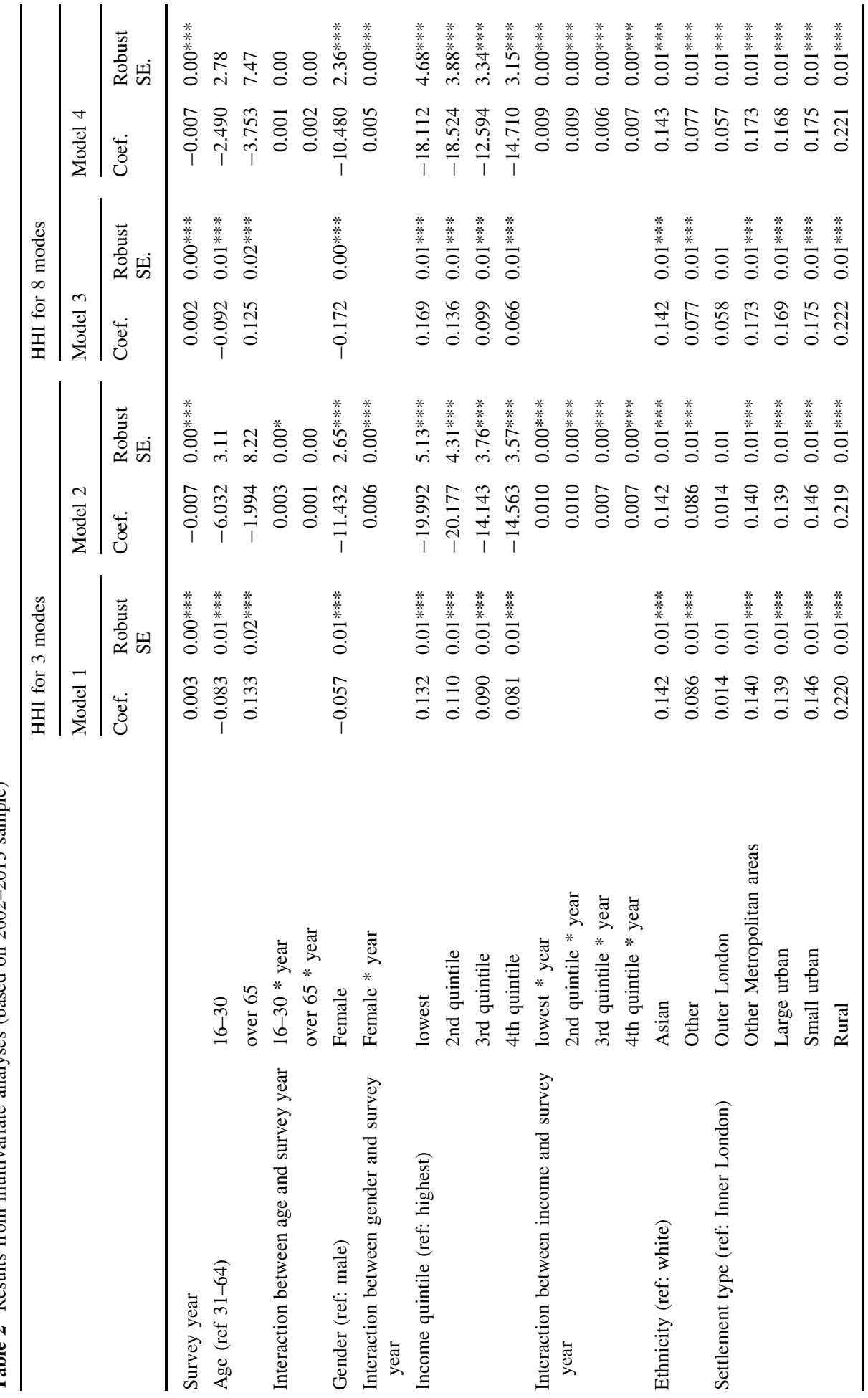




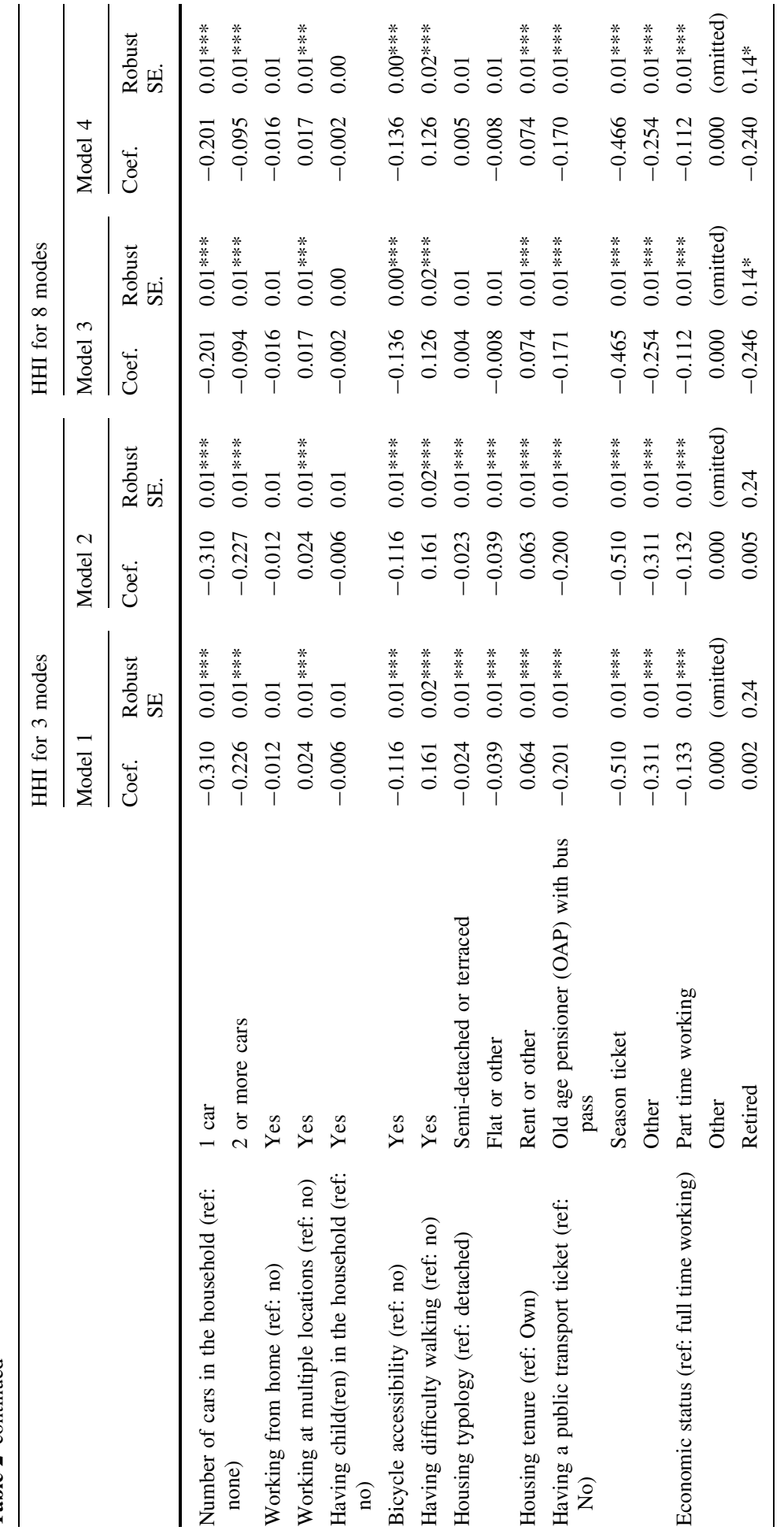




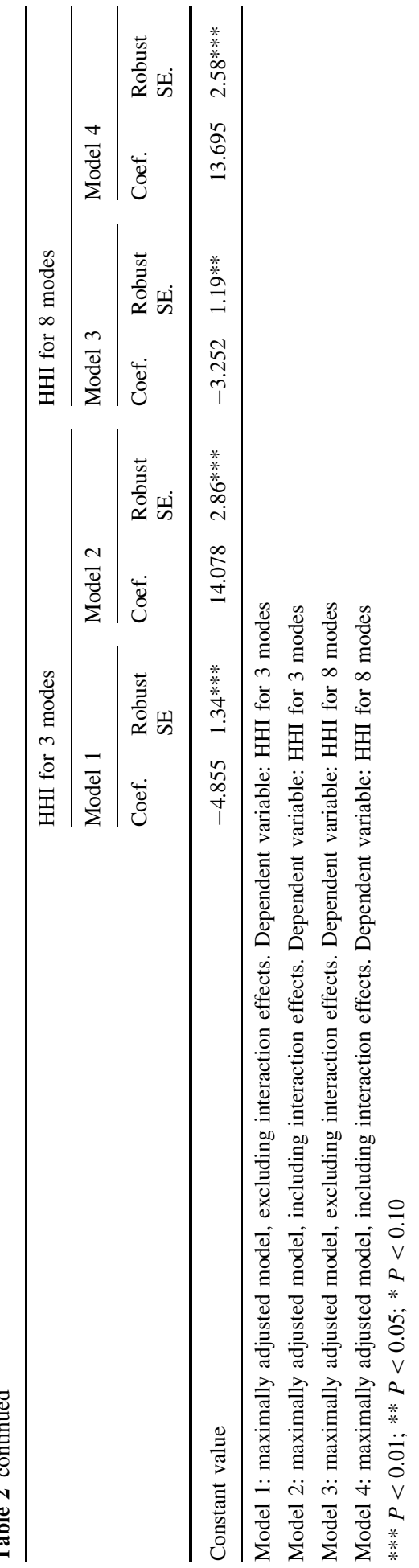


However, we did not see a clear effect of this in our explorations and therefore decided not to carry this forward to the maximally adjusted models. We did not find a significant interaction effect for car ownership, suggesting that the observed trends were explained by other characteristics.

The results of the multivariate analyses confirmed most of the previously reported trends. Between 2002 and 2015, the level of multimodality has decreased. This is indicated in Models 1 and 3 by the significant small positive coefficient for the survey year on the HH Indicators.

Women were, compared to men, more multimodal (Models 1 and 3), but over time their level of multimodality decreased compared to men (model 2 and 4). This corresponds with our observations in Fig. 3. The observations of Fig. 6 are also corroborated in the multivariate analyses. Compared to individuals with the highest income quintile, individuals with lower income quintiles had lower levels of multimodality (Models 1 and 3). Moreover, compared to the highest income quintile, individuals in other income quintiles reduced their level of multimodality between 2002 and 2015 more than individuals in the highest income category (Model 2 and 4). The effects sizes of these interactions effects of gender and income with the survey year appeared fairly similar in both models, independent whether the indicator was based on a consideration of three or eight modes.

Moreover, the analyses revealed several significant interaction effects. The youngest age category (individuals between 16 and 30 years of age) were becoming less multimodal over time compared to individuals aged between 30 and 64 years of age for the HHI for three modes (Model 2). However, lower ages still predict higher levels of multimodality (Model 1). The direction of the effect was similar for the HHI for eight modes, however this effect was non-significant (Models 3 and 4). One explanation could be that the reduction in multimodality for the youngest age category mainly took place before 2003 (Fig. 4) and the multivariate analyses only considered the years after 2002 due to data limitations.

The sensitivity analyses when the number of stages was also included in the models yielded fairly similar results for most correlates. All estimates for the coefficient of the interaction effects remained fairly similar ("Appendix 1").

\section{Discussion}

\section{Discussion of trends in multimodality}

Our analyses showed that the level of multimodality in England decreased between 1995 and 2015. Existing research had suggested an opposite trend. For example, Kuhnimhof et al. $(2011,2012 a)$ showed that there was a reduction in driving and an increase in the use of other modes, suggesting an increase in multimodality. However, their analyses implicitly adopted an aggregate understanding of multimodality. Moreover, all research investigating trends in multimodality based on few years which allows variations in sampling and responses to affect trends to a larger extent.

In contrast, our analyses focussed on individual multimodality on a more detailed stage level using the well-established, nationally representative National Travel Survey (NTS) of England, and covering 21 data points between 1995 and 2015. The fact that our detailed 
analyses revealed a different picture is important in understanding the relationship between the level of multimodality, changes in the modal split, and potential inequalities.

The trends in the level of multimodality diverged for different ethnic groups and for different income classes. This diverging trend was the clearest for income and were corroborated in the multivariate analyses. Individuals in the highest quintile had the highest level of multimodality and this level remained stable, whereas the level for the other four quintiles decreased. This may imply that income is increasingly discriminative in the number of modes available and its consequent use, which may indicate increased inequalities in transport availability and potentially accessibility to work and facilities based on income (see e.g. Lucas et al. 2016).

In contrast, the trends stratified by age and gender were converging, which implies that the differences in multimodality were becoming less pronounced between men and women and between age groups. More specifically, women and younger individuals, on average, decreased their level of multimodality towards the level of men and individuals older than 31 years, respectively. These findings are interesting as both groups are known to move in opposite directions in respect to car accessibility and ownership: younger individuals are known to be less likely to own a car, whereas women, in contrast, are known to have increasing ability to drive a car (DfT 2016a).

Most of our observation in the trend analyses were confirmed in the multivariate analyses. For age, the interaction effect was less strong, and in the model for eight modes, the interaction effect was no longer significant. One explanation could be that the reduction in multimodality for the youngest age category mainly took place before 2003 and the multivariate analyses only considered the years after 2002 due to data limitations.

The differences in the level of multimodality by the different stratifications-including, age, gender, ethnicity, urban status and car ownership-largely corresponded with previously reported correlates of multimodality in Great Britain (Heinen and Chatterjee 2015). For example, women were more multimodal then men, and the more urban the residential area was, the more multimodal the average inhabitant was. These corresponding findings implies stronger reliability of the findings. The level of multimodality stratified by the level of urbanisation remained fairly stable over time. This may suggest that the size of the settlement is an important predictor of multimodality in England. This finding may also suggest that changes in the proportion of residents living in areas with certain populations sizes, may directly influence the average level of multimodality.

\section{Discussion of trends in car use in relation to multimodality}

To place the trends in the level of multimodality in a wider context, we investigated the trends in car use, public transport use, bicycle use and walking. Between 1995 and 2015, absolute car use decreased, whereas car modal share increased between 1995 and 2002 and decreased slightly thereafter. Simultaneously, between 1995 and 2015, the level of multimodality decreased and the share of 'unimodal' car users increased.

However, car mode share has remained fairly stable since 2004 and multimodality has decreased in the similar period. This may indicate that the assumption that increasing multimodality goes hand in hand with a reduction in car use is incorrect as during a reduction in absolute car use, multimodality decreased as well. In other words, our results suggest that there is no necessary relationship between aggregate levels of car use and the average multimodality of individual travel patterns. This may imply that a reduction in actual use in car travel does not increase multimodality, or even and more importantly, that a higher level of multimodality may not result in less car-dependent societies. The question 
of whether the two trends are happening in parallel in countries is very much an empirical one, and a relationship between them should not be simply assumed.

An important contemporary discussion in transport is on the reduction in car ownership and use among millennials, so-called 'peak car' (Delbosc and Currie 2013; Frändberg and Vilhelmson 2011; Kuhnimhof et al. 2012b; McDonald 2015; Bastian et al. 2016), which has been documented for the UK (DfT 2015c; Kuhnimhof et al. 2012a; Le Vine and Jones 2012; McDonald et al. 2017; Rohr and Fox 2014). Our analyses showed that individuals aged 30 years or younger had overall higher levels of multimodality, but that this level was decreasing. This revealed an unexpected contrast: although car ownership and use is decreasing, so is their level of multimodality. It therefore appears that the absence of the car in individuals' modal mix, may suppress the level of multimodality. Younger individuals who abstain from using cars may not compensate the absence of this mode in their modal mix by the uptake of another mode and our findings may suggest that they may 'just' use the modes that are already in their modal mix more frequently. As such, although the commonly applied measures for multimodality may assess the level of mixing modes well, these indicators may be less effective to measure multimodality if the most dominant mode in our modal mix - the car-is not used. Nevertheless, the level of multimodality among younger millennials was still higher than that of other age groups.

Our analyses did not reveal a clear relationship between multimodality and car use. The reduction in car use occurred mainly in absolute numbers and less so compared relative to other modes. What does this finding imply for policy? A reduction in absolute car use is important, as it is likely to result in a reduction in air and noise pollution caused by transport. However, a change in the model mix and mode choice behaviour, measured by increased multimodality, may have more positive consequences in the long term. The uptake of new modes may increase self-efficacy in using several modes, which may ultimately result in a more sustained reduction in car use.

\section{Discussion on data, methodology and transferability}

We used a national representative, long-running, widely used data set: the National Travel Survey of Great Britain. Benefits of these data include that the survey has remained fairly similar over 20 years, includes a 1-week travel diary and is representative for England, allowing trend research on multimodality. Nevertheless, the NTS is a sample survey, and due to variations in the sample or changes in the survey, fluctuations in the results may be present. As a result, the NTS is not suitable for monitoring short-term trends or year-toyear changes, as is the case for all national travel surveys. In this paper, we have used the NTS for its primary intended use: to measure longer term trends in travel behaviour (DfT 2016b).

Nevertheless, the use of NTS is limited in other ways. The NTS is a survey that is conducted annually, but is a repeated cross-sectional survey and not a panel survey. As a consequence, we cannot investigate changes within an individual, or predictors of such changes. Additionally, we cannot draw any causal relationship on the explorations conducted. Moreover, given that the mean level of variability differs substantially between individuals - even between individuals in similar socio-economic groups-but the range is limited, the possibility of revealing significant changes over time is limited. 
In our trends we have seen several 'jumps'. We are not aware of any change in the NTS methodology that may explain these jumps. ${ }^{2}$ The NTS, and similar surveys should be used to measure longer term trends in travel behaviour. The observed jumps are an example why comparisons between 2 years, or trend analyses with a limited number of years are less reliable. In our analysis, we have addressed this problem by considering the longest period for which comparable data is available, as well as by presenting smoothed trends with centred moving averages.

As with any data source, groups that contain fewer cases are more vulnerable for fluctuation. In our case, some ethnic groups had limited representation in the NTS, and as a consequence the changes in their level of variability may be more prone to changes in the sample. Moreover, the ease of recruiting certain groups, e.g. low-income households, may have changed over time. This may results in the potential for more variation between years. Moreover, the participants of such groups may not be a good representation of such a group, and this may partly explain observed trends.

Our analyses showed that the trends were very similar independent of which indicator was applied. This indicates that for analysing trends in multimodality, the choice of indicator may not be that important, and indicators that are elementary to calculate and easy to interpret, e.g. number of modes used, highlight trends that are highly consistent with more sophisticated metrics. This does not imply that efforts into determining the most accurate measure of multimodality (for example by Diana and Pirra 2016) are not important, as these may give different (and better) results in more refined and disaggregate analysis. However, given that the trends in multimodality were hardly affected by the selection of the indicator, we would like to recommend taking the ease of interpretation into account, in addition to its ability to correctly measure multimodality in a variety of cases.

In contrast, the number of modes considered for the construction of indicators does make a difference for conclusions about temporal trends in multimodality. In some stratifications, different trends emerged between multimodality indices considering three and eight modes. This is understandable, if you consider the following example: if an individual has an equal split between being the main driver, walking and taking the bus, they would be considered very multimodal for the indicators considering three modes, but only moderately multimodal considering eight modes of transport. The opposite would be the case for an individual with an equal split between bus, rail and taxi. Our analysis does not lead us to recommend the use of indicators based on three or eight modes in future research. Rather, we recommend that future trend analyses take these differences into account, and depending on the location and the policy focus one of these measures may be prioritised.

Various measures of multimodality have been shown to be affected by the number of trips/stages an individual makes. The number of stages an individual made during the travel survey week survey may therefore affect the measured level of multimodality. If there were a decreases in the total number of trips, as it the case in NTS, this may impact the level of multimodality. However, the correlations between the number of stages and measurements of multimodality were only moderate. Moreover, the sensitivity analyses excluding individuals that recorded fewer than eight stages in the diary week and the inclusion of a variable indicated the number of stages in multivariate models, yielded fairly

\footnotetext{
${ }^{2}$ Based on NTS documentation and personal communication with an NTS officer from the Department for Transport.
} 
similar results, which indicates that the decline in number of trips did not have large influence in our observed reduces level of multimodality.

Our analyses focussed solely on England and therefore our findings are only applicable to the English context. Kuhnimhof et al. (2012a) showed that a decrease in car use was taking place in several western countries, i.e. Germany, France, Great Britain, Japan, Norway, and the USA. However, the effects on overall travel behaviour have been shown to differ between them. Although this reduction in car travel consequently resulted in an overall decrease in travel in France, Japan, and the USA, this decrease was compensated by an increase in other modes of transport in Great Britain and Germany. Thus, it is conceivable that the trends we uncovered may differ from the trends in other countries.

\section{Conclusion}

This paper explored the trends in multimodality in England. Our analyses showed, in contrast to reported trends in existing research, that the level of multimodality in England decreased between 1995 and 2015. These trends stratified by age and gender ownership were converging, although they were diverging for ethnicity and income. This may imply that income is increasingly discriminative in the number of modes available and its consequent use, which may indicate increased in inequalities in transport availability. In addition, we found that the car mode share has remained fairly stable since 2004, whereas multimodality decreased. This suggests that there is no necessary relationship between aggregate levels of car use and the average multimodality of individual travel patterns. A comparison of trends between multiple countries using the same definitions and indicators may further improve our understanding of whether this trend (less car use and less multimodality) is location specific. This may help policy-makers specify where most efforts need to be made - either by reducing car use, or by stimulating the use of other modes.

Acknowledgements The NTS 1995-2001 and 2002-2015 special licence data sets of the British Department for Transport (Department for Transport 2015d, 2016c) were kindly provided by the Economic and Social Data Service (ESDS) through the UK Data Archive at the University of Essex, Colchester. The responsibility for the analysis, interpretation and all conclusions drawn from the data lies entirely with the authors.EH has been funded by The Netherlands Organisation for Scientific Research, VENI-Grant (016.145.073).

\section{Compliance with ethical standards}

Conflict of interest The authors declare that there are no conflicts of interest.

Open Access This article is distributed under the terms of the Creative Commons Attribution 4.0 International License (http://creativecommons.org/licenses/by/4.0/), which permits unrestricted use, distribution, and reproduction in any medium, provided you give appropriate credit to the original author(s) and the source, provide a link to the Creative Commons license, and indicate if changes were made.

\section{Appendix 1}

See Table 3. 


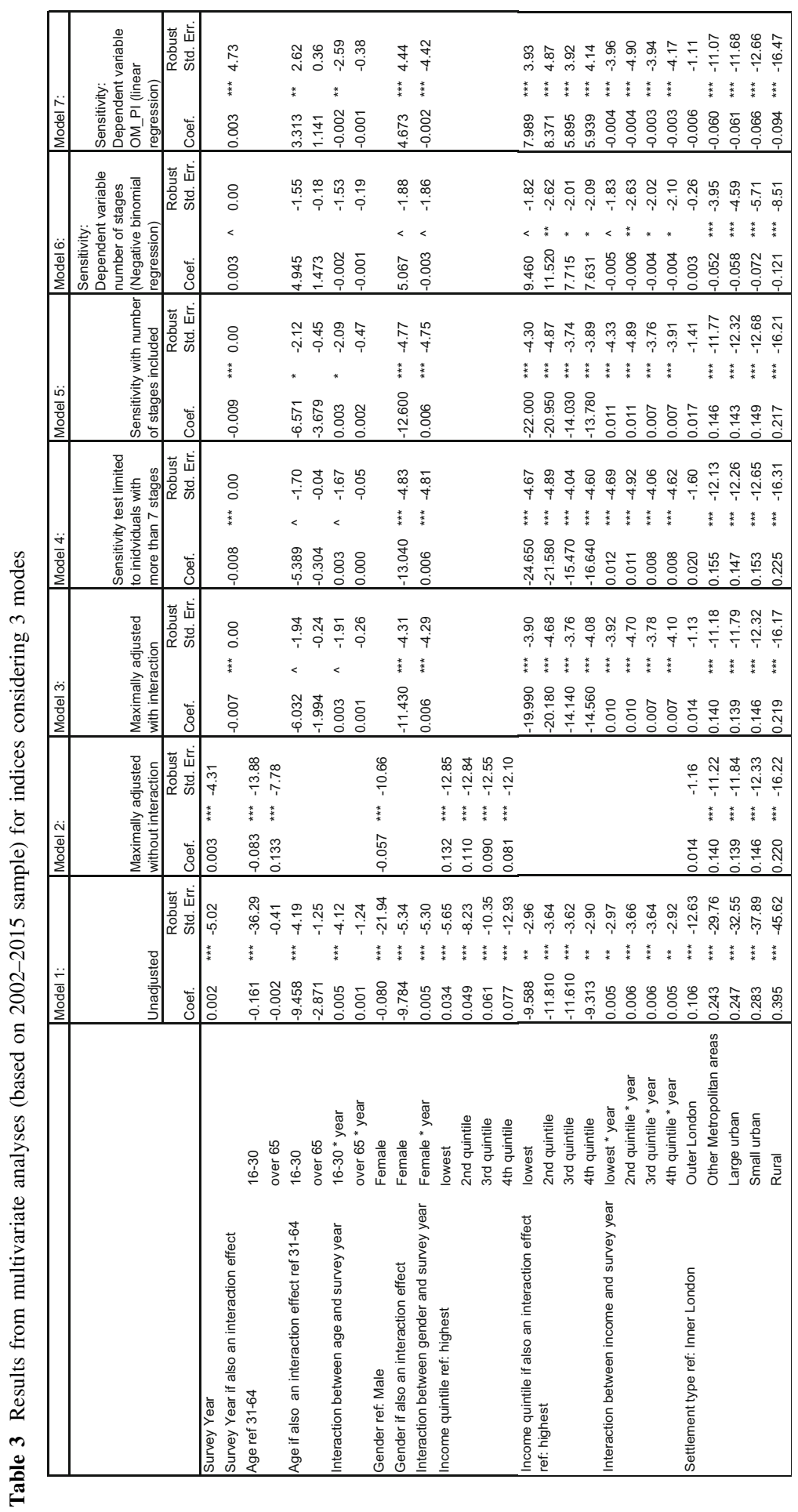




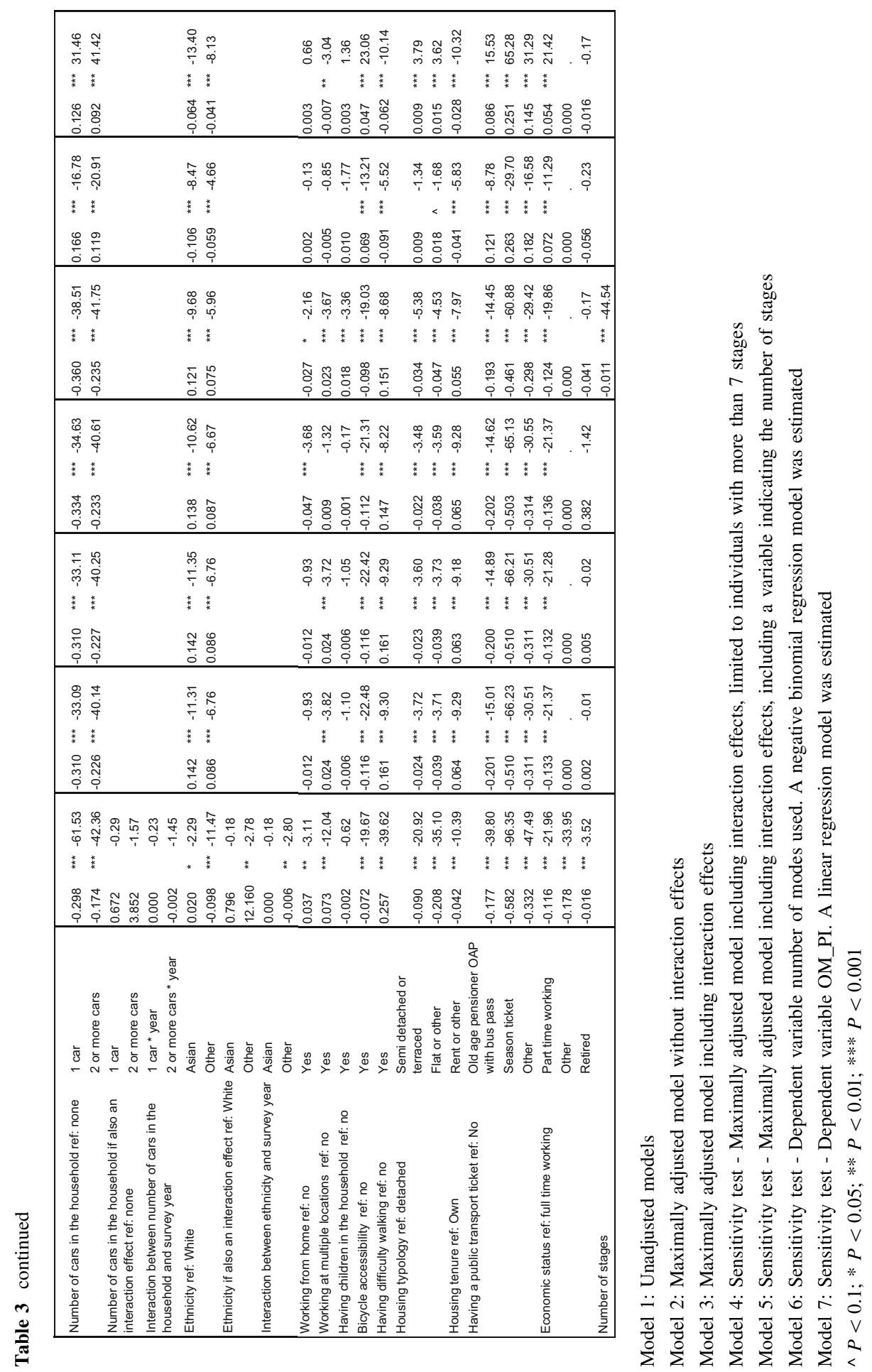




\section{References}

Bastian, A., Börjesson, M., Eliasson, J.: Explaining “peak car” with economic variables. Transp. Res. Part A. Policy Pract. 88, 236-250 (2016)

Block-Schachter, D.: The Myth of the Single Mode Man: How the Mobility Pass Better Meets Actual Travel Demand (Master's thesis). MIT, Massachusetts(USA), (2009)

Buehler, R., Hamre, A.: The multimodal majority? Driving, walking, cycling, and public transportation use among American adults. Transportation 42, 1081-1101 (2015)

Buehler, R., Hamre, A.: An examination of recent trends in multimodal travel behavior among American motorists. Int. J. Sustain. Transp. 10(4), 354-364 (2016)

Delbosc, A., Currie, G.: Causes of youth licensing decline: a synthesis of evidence. Transp. Rev. 33(3), 271-290 (2013)

Department for Transport (DfT). National Travel Survey. Mode use, 2005-2015: a View Into a Travel Week. https://files.datapress.com/sport/dataset/national-travel-survey-a-view-into-a-travel-week/201701-18T09:37:39/LSR191\%20Department\%20for\%20Transport\%20-\%20National\%20Travel\% 20Survey\%20A\%20View\%20into\%20a\%20Travel\%20Week.pdf (2015a). Accessed 21 June 2017

Department for Transport (DfT). National Travel Survey: Change in Travel Since 1965. https://www.gov. uk/government/uploads/system/uploads/attachment_data/file/457732/nts2014-factsheet.pdf (2015b). Accessed 7 Dec 2016

Department for Transport (DfT). Understanding the Drivers of Road Travel: Current Trends in and Factors Behind Roads Use. https://www.gov.uk/government/publications/understanding-the-drivers-of-roadtravel-current-trends-in-and-factors-behind-roads-use (2015c). Accessed 16 Jan 2016

Department for Transport (DfT). National Travel Survey, 1995-2001: Special License Access. [Computer File] UK Data Service (2015d). SN: 7804

Department for Transport (DfT). Collection National Travel Survey Statistics. https:/www.gov.uk/ government/collections/national-travel-survey-statistics (2016a). Accessed 7 Dec 2016

Department for Transport (DfT). National Travel Survey. Data Extract User Guide, 1995-2015. https:// www.gov.uk/government/collections/national-travel-survey-statistics (2016b). Accessed 25 Apr 2017

Department for Transport (DfT). National Travel Survey, 2002-2014: Special License Access. [Data Collection], 4th Edition. UK Data Service (2016c). SN: 7553

Diana, M., Pirra, M.: A comparative assessment of synthetic indices to measure multimodality behaviours. Transp A Transp. Sci. 12(9), 771-793 (2016). doi:10.1080/23249935.2016.1177133

EC (2014) Do the right mix. European Commission's Sustainable Urban Mobility Campaign. European Commission Directorate-General for Mobility And Transport. http://www.polisnetwork.eu/ publicnews/238/45/Sustainable-urban-mobility-Commission-campaign-boosts-support-to-fightcongestion-and-pollution. Accessed 16 Jan 2016

Frändberg, L., Vilhelmson, B.: More or less travel: personal mobility trends in the Swedish population focusing gender and cohort. J. Transp. Geogr. 19(6), 1235-1244 (2011)

Heinen, E., Chatterjee, K.: The same mode again? An exploration of mode choice variability in Great Britain using the national travel survey. Transp. Res. Part A. Policy Pract. 78, 266-282 (2015)

Heinen, E., Ogilvie, D.: Variability in baseline travel behaviour as a predictor of changes in commuting by active travel, car and public transport: a natural experimental study. J. Transp. Health. 3(1), 77-85 (2016)

Le Vine, S., Jones, P.: On the Move: Making sense of car and train travel trends in Britain. RAC Foundation, London (2012)

Lucas, K., Bates, J., Moore, J., Carrasco, J.A.: Modelling the relationship between travel behaviours and social disadvantage. Transp. Res. Part A. Policy Pract. 85, 157-173 (2016)

Kroesen, M.: Modeling the behavioral determinants of travel behavior: an application of latent transition analysis. Transp. Res. Part A. Policy Pract. 65, 56-67 (2015)

Kuhnimhof, T., Armoogum, J., Buelher, R., Dargay, J., Denstadli, J.M., Yamamoto, T.: Men shape a downward trend in car use among young adults-evidence from six industrialised countries. Transp. Rev. 32(6), 761-799 (2012a)

Kuhnimhof, T., Buelher, R., Wirtz, M., Kalinowska, D.: Travel trends among young adults in Germany: increasing multimodality and declining car use for men. J. Transp. Geogr. 24, 443-450 (2012b)

Kuhnimhof, T., Buehler, R., Dargay, J.: A new generation: travel trends among young 31 Germans and Britons. Transp. Res. Rec. 2230, 58-67 (2011)

Mattioli, G.: Where sustainable transport and social exclusion meet: households without cars and car dependence in Great Britain. J. Environ. Policy Plan. 16(3), 379-400 (2014)

McDonald, N.: Are millennials really the 'go nowhere' generation? J. Am. Plann. Assoc. 81(2), 90-103 (2015) 
McDonald, N., Mattioli, G., Marsden, G.: Understanding the Impact of the Changing Labour Market on Millennial Mobility: A Study of the UK Experience 1995-2014, Transportation Research Board 96th Annual Meeting, Washington, D.C., 8-12 January 2017

Molin, E., Mokhtarian, P., Kroesen, M.: Multimodal travel groups and attitudes: a latent class cluster analysis of Dutch travelers. Transp. Res. Plan A. Policy Pract. 83, 14-29 (2016)

NatCen Social Research (2016). National travel survey 2015. Technical Report. https://www.gov.uk/ government/uploads/system/uploads/attachment_data/file/550854/nts-technical-report-2015.pdf. Accessed: 26 June 2017)

Nobis, C.: Multimodality - facets and causes of sustainable mobility behavior. Transp. Res. Rec. 2010, 35-44 (2007)

Olafsson, A.S., Nielsen, T.S., Carstensen, T.A.: Cycling in multimodal transport behaviours: exploring modality styles in the Danish population. J. Transp. Geogr. 5, 123-130 (2016)

Papke, L.E., Wooldridge, J.M.: Econometric methods for fractional response variables with an application to 401(K) plan participation rates. J. Appl. Econom. 11, 619-632 (1996)

Rofique, J., Humphrey, A., Pickering, K., Tipping, S.:National Travel Survey 2010 Technical Report, Department for Transport, London (2010)

Rohr, C., Fox, J.: Evidence Review of Car Traffic Levels in Britain. RAND Corporation, Cambridge (2014)

Scheiner, J., Chatterjee, K., Heinen, E.: Key events and multimodality: a life course approach. Transp. Res. Part A. Policy Pract. 91, 148-165 (2016)

Susilo, Y.O., Axhausen, K.W.: Repetitions in individual daily activity-travel-location patterns: a study using the Herfindahl-Hirschman Index. Transportation 41, 995-1011 (2014)

Streit, T., Allier, C.-E., Weiss, C., Chlond, B., Vortisch, P.: Changes in variability and flexibility of individual travel in Germany: trends and drivers. Transp. Res. Rec. 2496, 10-19 (2015)

Eva Heinen is a University Academic Fellow (tenure track assitant professor) in the Institute for Transport Studies, University of Leeds. Eva is interested in individual travel behaviour and behavioural change. Her work focusses on the intersection of transport and health and she has worked on various topics including active travel, cycling, evaluating interventions in the built environment on travel behaviour, and variability and stability of behaviour.

Giulio Mattioli is Research Fellow in Sustainable Transport at the Sustainability Research Institute and the Institute for Transport Studies, University of Leeds. He has researched issues concerning car dependence, transport disadvantage and affordability. His current work investigates the political economy of energyintensive transport systems. 